Article

\title{
A Revised Phylogeny of the Mentha spicata Clade Reveals Cryptic Species
}

\author{
Olivier C. G. Heylen ${ }^{1, *}$, Nicolas Debortoli ${ }^{2}$, Jonathan Marescaux ${ }^{2}$ and Jill K. Olofsson ${ }^{3}$ \\ 1 Hof ter Laken, Hofdreef 5, B-2221 Booischot, Belgium \\ 2 E-BIOM SA, 5/7 Rue Godefroid, B-5000 Namur, Belgium; n.debortoli@e-biom.com (N.D.); \\ j.marescaux@e-biom.com (J.M.) \\ 3 Section for GeoGenetics, GLOBE Institute, University of Copenhagen, Øster Farimagsgade 5, bygning 7, \\ DK-1353 Copenhagen, Denmark; jill.olofsson@sund.ku.dk \\ * Correspondence: olivier.heylen@telenet.be
}

check for updates

Citation: Heylen, O.C.G.; Debortoli, N.; Marescaux, J.; Olofsson, J.K. A Revised Phylogeny of the Mentha spicata Clade Reveals Cryptic Species. Plants 2021, 10, 819. https://doi.org/ 10.3390/plants10040819

Academic Editor: Igor Bartish

Received: 24 February 2021

Accepted: 18 April 2021

Published: 20 April 2021

Publisher's Note: MDPI stays neutral with regard to jurisdictional claims in published maps and institutional affiliations.

Copyright: (c) 2021 by the authors. Licensee MDPI, Basel, Switzerland. This article is an open access article distributed under the terms and conditions of the Creative Commons Attribution (CC BY) license (https:// creativecommons.org/licenses/by/ $4.0 /)$.

\begin{abstract}
The genus Mentha is taxonomically and phylogenetically challenging due to complex genomes, polyploidization and an extensive historical nomenclature, potentially hiding cryptic taxa. A straightforward interpretation of phylogenetic relationships within the section Mentha is further hindered by dominant but outdated concepts on historically identified hybrid taxa. Mentha spicata is traditionally considered to be of hybrid origin, but the evidence for this is weak. Here, we aim to understand the phylogenetic relationships within the section Mentha using large sample sizes and to revisit the hybrid status and identity of M. spicata. We show that two of three traditional species in the subsection Spicatae are polyphyletic, as is the subsection as a whole, while the real number of cryptic species was underestimated. Compared to previous studies we present a fundamentally different phylogeny, with a basal split between M. spicata s.s. and M. longifolia s.s. Cluster analyses of morphological and genotypic data demonstrate that there is a dissociation between morphologically and genotypically defined groups of samples. We did not find any evidence that M. spicata is of hybrid origin, and we conclude its taxonomic status should be revised. The combination of genetic and phenotypic information is essential when evaluating hyperdiverse taxonomic groups.
\end{abstract}

Keywords: cryptic species; discriminant analysis; hyperdiversity; ITS sequences; Mentha; morphometrics; phylogenetics; porous genomes; SCoT; Spicatae

\section{Introduction}

An important goal in evolutionary biology is to understand the evolutionary processes that promote biodiversity and taxonomic abundance [1]. Describing and analyzing phenotypic and genotypic variability is important to understand how variation is structured [2], which sheds light not only on the existing diversity but also on the genotype-phenotype links and their interactions with the environment. This includes aspects of polyploidy and interspecific hybridization [3], epigenetic factors [4] and plasticity, all essential in understanding the processes shaping biodiversity and speciation [5]. Central to understand the evolutionary process that shapes biodiversity is the concept of what constitutes a 'species' [6,7]. The classical species concept has largely been questioned in the genomic area, especially for plants. Populations of genetically structured species can sometimes be strongly divergent and, when put in a fragmented metapopulation context with incomplete reproductive isolation, specific assortments can often be cryptic [8-12]. However, DNA and species delimitation criteria have been successfully used for the detection of such species [13-16]. While molecular markers can be useful in deciphering complex relationships, they can sometimes be insufficient on their own (e.g., [17]).

Cryptic and hyperdiverse species complexes [6] with large distribution ranges are excellent model systems for studying the evolutionary processes shaping biodiversity as they harbor an abundance of genetic material for divergent selection and local adaptation. 
However, the genotype-phenotype links are not always clear in such taxa [18], and hence it can be difficult to describe their taxonomic structure [7]. With no clear concept of species delimitations, describing the genetic distance between populations and species in these groups can also be problematic. In addition, some hyperdiverse taxa show large amounts of gene flow, further complicating genetic groupings and taxonomic assignments [1,19].

Here, we use the genus Mentha (mints, subtribe Menthinae, family Lamiaceae; [20,21]), with a particular focus on the Spicate mint complex (subsect. Spicatae belonging to sect. Mentha, sensu Briquet [22]), to demonstrate the problems with taxonomic assignments and phylogenetic reconstructions in plant genera with large interspecific overlaps in phenotype and genotype. Further, this genus is known as a model for other polyploid taxa [23]. Moreover, taxonomic controversies have a long tradition in Lamiaceae, with the Menthinae being one of the most notoriously difficult groups [24], and therefore, a sound phylogenetic framework is needed [21].

Many authors (e.g., [25-32]) have already described the complex (morphological, chemical and molecular) diversity in mints. The complicated historical nomenclature (2630 names for Mentha on https://www.tropicos.org and https://www.catalogueoflife.org; accessed on 17 January 2021) strongly contrasts with the apparent simplicity presented by some authors nowadays. For example, Tucker and Naczi [33] list 18 species of Mentha and a high number of provisional subspecies. Additional species within the subsection Spicatae have also been described by, e.g., Borissova [34], Jamzad [35], Jančić [36] and Conn and Duval [37]. Despite the historical description of a large array of mint taxa (e.g., [38,39]), currently only five 'basic' species in Mentha sect. Mentha are recognized. In addition, numerous subspecies, varieties (mostly cultivars) and hybrids are also mentioned [33]. However, the historic richness in mint names likely reflects hyperdiversity and hidden cryptic species [40].

Spicate mints are currently divided into three basic species, M. spicata L., M. longifolia (L.) L. and M. suaveolens Ehrh. (nomenclature follows Tucker and Naczi [33] unless otherwise stated), with $M$. spicata commonly accepted as an ancient stabilized polyploid hybrid between the latter two species [41]. The idea of $M$. spicata as a hybrid species is linked to its well-promoted cultivation status [42-45] and to the generally accepted hypothesis that it behaves as a segmental allopolyploid with parental characters occasionally segregating [41,46-51]. Inspired by the work of Harley [48], Lebeau [52-54] described two subspecies of M. spicata, the 'cultivated' M. spicata subsp. glabrata (Lej. \& Courtois) Lebeau, with glabrous leaves, and 'the wild' M. spicata subsp. spicata, with hairy leaves. However, their distinction as different subspecies is all but clear, and its taxonomic value has been questioned [55]. In addition, it seems that the taxonomic units M. spicata and even more so M. $\times$ villosa Huds. (and other authors) have sometimes been used as a taxonomic 'garbage bin'. This has complicated phylogenetic, biogeographical and evolutionary studies. In particular, the phenotypic and especially the genotypic variation within and among the currently recognized mint species remains largely undescribed [56]. To resolve these issues, the integration of phenotypic and genotypic information of an increased number of individuals per taxonomic unit is needed, provided an appropriate experimental setting to avoid misleading associations between phenotypes and genotypes.

It is indeed highly relevant to explore more phenotypic features for Mentha sect. Mentha than has been done so far. Much of the past morphological research concentrated on a limited number of features (usually about 10-30; e.g., [31,57,58]), focused on variables that are not always feasible or evaluated morphology in unstandardized environments [59-61]. Very few studies have focused on more in-depth analyses of macroand/or micromorphology, such as microstructure features in palynological studies [59] or different anatomical/microscopical features assessed in M. suaveolens [62]. Moreover, Bokić [63] measured many morphological and phytochemical variables (including stamen features with high intraspecific variability) for a large number of samples but did not perform genetic analyses. Other studies evaluated morphology in a standardized setting, but the applied genetic markers are meanwhile outdated (e.g., RAPD in [64]). In general, 
detailed morphological datasets from plants grown in standardized conditions are rare, and if present, they usually lack complementary molecular data (among the exceptions is [65]). Moreover, extensive studies concentrating on nuclear marker (ITS) information and considering at least three species of Spicate mints with sample sizes $n>20$ are limited to just a very few (e.g., $[66,67])$. Remarkably in such cases, morphological data are lacking, and one must resort to plant labels projected on sequence dendrograms, giving way to dubious interpretations and vicious circles. Notwithstanding the lack of adequate and versatile information, the conclusion that $M$. spicata is an allotetraploid hybrid of the diploid species M. longifolia and M. suaveolens is repeatedly echoed, which nails the Spicate mint phylo-geny down to a simple triad with M. spicata in the middle (e.g., [33] pp. 8-9). To synthesize, based on existing data, the make-up of a detailed overview of the genotype-phenotype relationships within Spicate mints is highly problematic, which complicates the derivation of sound interpretations of phylogenetic relationships within the genus.

Here, we introduce a fundamentally different viewpoint on the evolutionary relationships among Spicate mints. We present an innovative phylogeny implying refreshing insights on previous hybridization concepts and cryptic taxa. By combining genetic and morphological data, we were able to discern cryptic mint species and uncover new taxonomic units. A strong phenotype pattern emerges that seems largely decoupled from any specific genetic input data but is nevertheless in line with the ITS-based phylogenetic backbone. We show evidence that the taxonomy and hybridization status of M. spicata should be reconsidered, thereby pointing to the danger of traditional concepts attached to outdated but inflated nomenclature so typical for cryptic taxa in general. With this study, we also illustrate the importance of simultaneously incorporating phenotypic and genotypic data of a large number of samples per taxonomic unit to understand the biodiversity and species richness in hyperdiverse taxonomic groups that likely hide a number of cryptic taxa.

\section{Results}

\subsection{DNA Amplification, Phylogenetic Reconstruction and ITS Clusters}

The amplification and Sanger sequencing of the ITS1-5.8S-ITS2 region was successful for all the samples, resulting in an alignment of 162 sequences (690 bp of which 167 sites are polymorphic). Some of the samples showed noisy chromatograms, but reamplification and resequencing with a more stringent protocol resulted in clear sequences for all but two samples. For sample 626, multiple peaks were observed that can be explained by at least four phased sequences $(626 a-d)$. Due to the noisiness of the chromatogram for sample 499, even with the more stringent protocol, only the major sequences were reported. For another twelve samples, the chromatograms indicate the presence of more than two sequences (Table S1), suggesting polyploidy or pseudogenes (gene duplications followed by mutations). However, only the two major sequences are reported here, as cloning would be needed to distinguish the minor sequence variants (peaks $<50 \%$ the size of the major peaks).

Although the Bayesian phylogeny shows some nodes with good support (posterior probability (PP) $\geq 0.70$; [57]), most relationships are only moderately to poorly supported (Figure 1). There are, however, recognizable phylogenetic clusters that are taxonomically relevant (Figure 1). However, the basal split between what is interpreted by us as M. longifolia sensu strictu (cf. lectotype of M. longifolia (L.) L. [68]) and M. suaveolens is unsupported (Figure 1); notably, these are the only two Spicate taxa commonly considered as 'pure' species. Clearly, the traditionally recognized Spicate mint species are mostly polyphyletic (Figure 1; Table 1). 


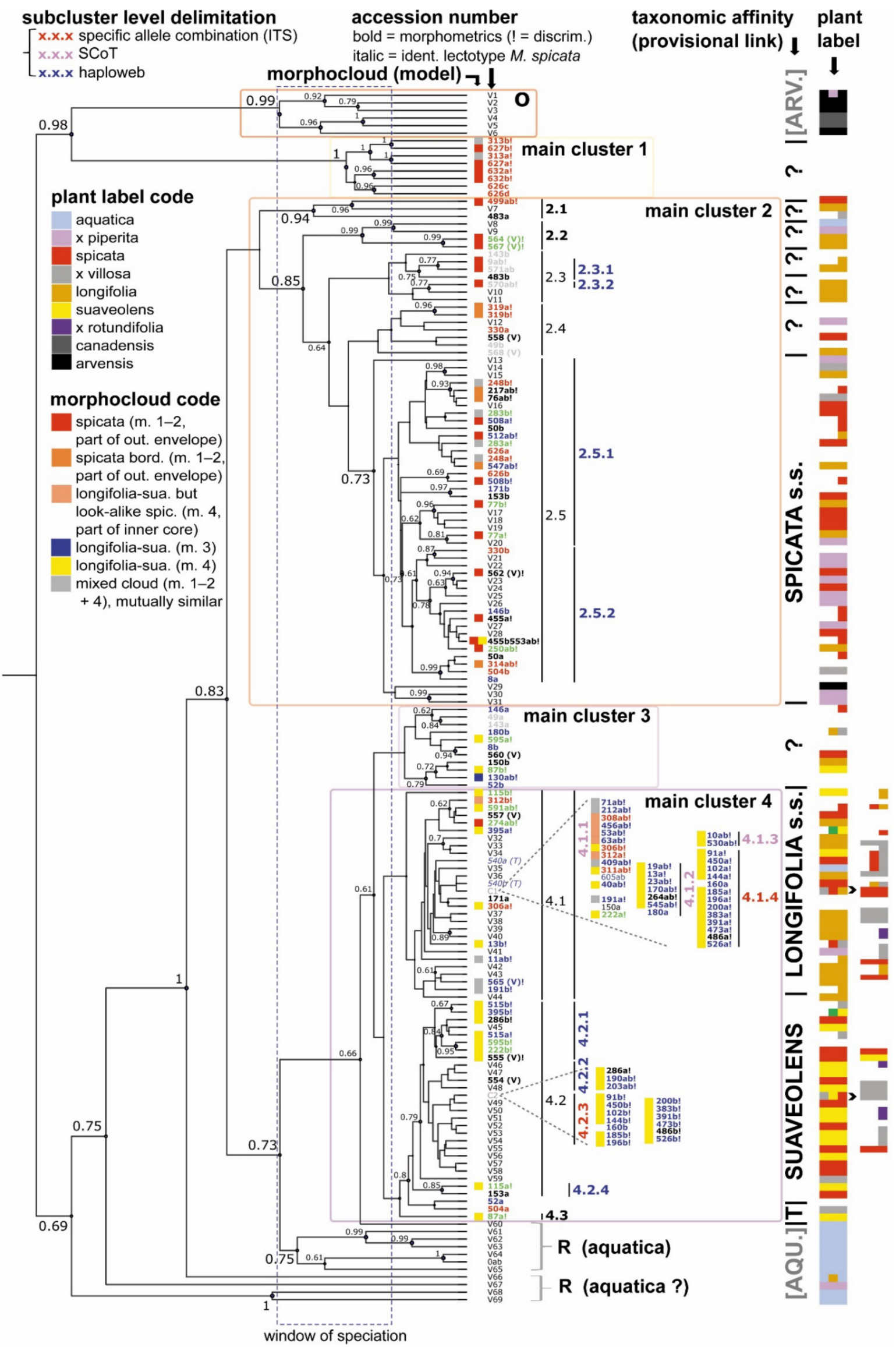

Figure 1. Ultrametric tree showing phylogenetic relationships within the genus Mentha subsect. Spicatae. 
Table 1. Correspondence of Ward's groups and traditional cryptic species perceptions using plant labels. Blocks coded by Ward's groups are presented with genetic (sub)cluster codes and corresponding specimen units (plants). Ward's groups can be compared to the available set of plant labels, accepting that for hybrid samples parent selection is done with the one parent most fitting the category becoming selected ('label assignment'). Additionally, some explanation is given about the plant names as traditionally used. Color legend: see Figure 1.

\begin{tabular}{|c|c|c|c|c|c|c|c|}
\hline $\begin{array}{l}\text { Accession } \\
\text { Number }\end{array}$ & $\begin{array}{c}\text { Plant Labels } \\
\text { (Only 1-2 Boxes } \\
\text { Means Informal } \\
\text { Label, } 3 \text { Boxes } \\
\text { Means ‘Officially' } \\
\text { Labeled) }\end{array}$ & $\begin{array}{l}\text { Label Assignment to One } \\
\text { of the Parental Species } \\
\text { (Criterium Least 'Pattern } \\
\text { Disturbing' Parent) }\end{array}$ & Perceived Taxa & $\begin{array}{l}\text { Morphotype } \\
\text { (Ward's Group } \\
\text { Ranking) }\end{array}$ & $\begin{array}{l}\text { Cluster } \\
\text { ITS }\end{array}$ & $\begin{array}{l}\text { Subcluster } \\
\text { ITS + } \\
\text { HAPL + } \\
\text { SCOT }\end{array}$ & $\begin{array}{l}\text { Specimen } \\
\text { Unit }\end{array}$ \\
\hline 286 & & & \multirow{9}{*}{$\begin{array}{l}\text { M. spicata (subsp. glabrata) or } \\
\text { M. } \times \text { cordifolia }\end{array}$} & 1 & 4.2 & $4.2 .2 / 4.2 .1$ & $4.2 .2 \times 4.2 .1$ \\
\hline 455 & & & & 1 & 2.5 & 2.5 .2 & 2.5 .2 \\
\hline $562(\mathrm{~V})$ & & & & 1 & 2.5 & 2.5 .2 & 2.5 .2 \\
\hline 627 & & & & 1 & 1.0 & - & 1.0 .0 \\
\hline 217 & & & & 1 & 2.5 & 2.5 .1 & 2.5 .1 \\
\hline $555(\mathrm{~V})$ & & & & 1 & 4.2 & 4.2 .1 & 4.2 .1 \\
\hline 499 & & & & 1 & 2.1 & - & 2.1 .0 \\
\hline 222 & & & & 1 & $4.1 / 4.2$ & $4.1 .1 / 4.2 .1$ & $4.1 .1 \times 4.2 .1$ \\
\hline 409 & & & & 1 & 4.1 & 4.1 .1 & 4.1 .1 \\
\hline 570 & & & \multirow{5}{*}{$\begin{array}{l}\text { M. longifolia incl. } M . \text { asiatica, } M \text {. } \\
\text { longifolia subsp. hymalaiensis, } M \text {. } \\
\text { longifolia subsp. capensis }\end{array}$} & 1 & 2.3 & 2.3 .2 & 2.3 .2 \\
\hline 53 & & & & 2 & 4.1 & 4.1 .1 & 4.1 .1 \\
\hline $564(\mathrm{~V})$ & & & & 2 & 2.2 & - & 2.2 .0 \\
\hline $567(\mathrm{~V})$ & & & & 2 & 2.2 & - & 2.2 .0 \\
\hline 571 & & & & 2 & 2.3 & 2.3 .1 & 2.3 .1 \\
\hline 595 & & & \multirow{9}{*}{ M. longifolia } & 2 & $3.0 / 4.2$ & $3.0 / 4.2 .1$ & $3.0 .0 \times 4.2 .1$ \\
\hline 71 & & & & 2 & 4.1 & 4.1 .1 & 4.1 .1 \\
\hline 212 & & & & 2 & 4.1 & 4.1 .1 & 4.1 .1 \\
\hline 130 & & & & 2 & 3.0 & - & 3.0 .0 \\
\hline 191 & & & & 2 & 4.1 & 4.1 .1 & 4.1 .1 \\
\hline 308 & & & & 2 & 4.1 & 4.1 .1 & 4.1.1 \\
\hline 312 & & & & 2 & 4.1 & 4.1 .1 & 4.1 .1 \\
\hline 456 & & & & 2 & 4.1 & 4.1 .1 & 4.1 .1 \\
\hline 11 & & & & 3 & 4.1 & 4.1 .1 & 4.1 .1 \\
\hline 77 & & & \multirow{8}{*}{$\begin{array}{l}\text { M. longifolia or M. spicata subsp. } \\
\text { tomentosa/subsp. condensata/M. } \\
\text { microphylla }\end{array}$} & 3 & 2.5 & 2.5 .1 & 2.5 .1 \\
\hline 250 & & & & 3 & 2.5 & 2.5 .2 & 2.5 .2 \\
\hline 283 & & & & 3 & 2.5 & 2.5 .1 & 2.5 .1 \\
\hline 319 & & & & 3 & 2.4 & - & 2.4 .0 \\
\hline 311 & & & & 3 & 4.1 & 4.1 .1 & 4.1 .1 \\
\hline 248 & & & & 3 & 2.5 & 2.5 .1 & 2.5 .1 \\
\hline 306 & & & & 3 & 4.1 & 4.1 .1 & 4.1 .1 \\
\hline 450 & & & & 3 & $4.1 / 4.2$ & $4.1 .4 / 4.2 .3$ & $4.1 .4 \times 4.2 .3$ \\
\hline 313 & & & \multirow{3}{*}{$\begin{array}{l}\text { M. longifolia (probably) or } \\
\text { exceptionally M. spicata (?) }\end{array}$} & 4 & 1.0 & - & 1.0 .0 \\
\hline 591 & & & & 4 & 4.1 & 4.1 .1 & 4.1 .1 \\
\hline 632 & & & & 4 & 1.0 & - & 1.0 .0 \\
\hline 274 & & & \multirow{10}{*}{ M. longifolia or hybrid } & 4 & 4.1 & 4.1 .1 & 4.1 .1 \\
\hline 553 & & & & 4 & 2.5 & 2.5 .2 & 2.5 .2 \\
\hline 512 & & & & 4 & 2.5 & 2.5 .1 & 2.5 .1 \\
\hline 545 & & & & 4 & 4.1 & 4.1 .2 & 4.1 .2 \\
\hline 9 & & & & 4 & 2.3 & 2.3 .1 & 2.3 .1 \\
\hline 91 & & & & 4 & $4.1 / 4.2$ & $4.1 .4 / 4.2 .3$ & $4.1 .4 \times 4.2 .3$ \\
\hline 203 & & & & 4 & 4.2 & 4.2 .2 & 4.2 .2 \\
\hline 395 & & & & 5 & $4.1 / 4.2$ & $4.1 .1 / 4.2 .1$ & $4.1 .1 \times 4.2 .1$ \\
\hline 547 & & & & 5 & 2.5 & 2.5 .1 & 2.5 .1 \\
\hline $565(\mathrm{~V})$ & & & & 5 & 4.1 & 4.1 .1 & 4.1 .1 \\
\hline 508 & & & \multirow{8}{*}{$\begin{array}{c}\text { M. spicata subsp. spicata or } M . \\
\times \text { villosa }\end{array}$} & 5 & 2.5 & 2.5 .1 & 2.5 .1 \\
\hline 391 & & & & 5 & $4.1 / 4.2$ & $4.1 .4 / 4.2 .3$ & $4.1 .4 \times 4.2 .3$ \\
\hline 473 & & & & 5 & $4.1 / 4.2$ & $4.1 .4 / 4.2 .3$ & $4.1 .4 \times 4.2 .3$ \\
\hline 486 & & & & 5 & $4.1 / 4.2$ & $4.1 .4 / 4.2 .3$ & $4.1 .4 \times 4.2 .3$ \\
\hline 530 & & & & 5 & 4.1 & 4.1 .3 & 4.1 .3 \\
\hline 515 & & & & 5 & 4.2 & 4.2 .1 & 4.2 .1 \\
\hline 383 & & & & 5 & $4.1 / 4.2$ & $4.1 .4 / 4.2 .3$ & $4.1 .4 \times 4.2 .3$ \\
\hline 526 & & & & 5 & $4.1 / 4.2$ & $4.1 .4 / 4.2 .3$ & $4.1 .4 \times 4.2 .3$ \\
\hline 264 & & & \multirow{8}{*}{$\begin{array}{l}\text { M. suaveolens (subsp. suaveolens) } \\
\text { or its hybrids including } M . \times \\
\text { villosa (subsp. alopecuroides) and } \\
\text { M. } \times \text { rotundifolia }\end{array}$} & 6 & 4.1 & 4.1 .2 & 4.1 .2 \\
\hline 102 & & & & 6 & $4.1 / 4.2$ & $4.1 .4 / 4.2 .3$ & $4.1 .4 \times 4.2 .3$ \\
\hline 144 & & & & 6 & $4.1 / 4.2$ & 4.1.4/4.2.3 & $4.1 .4 \times 4.2 .3$ \\
\hline 40 & & & & 6 & 4.1 & 4.1 .1 & 4.1 .1 \\
\hline 23 & & & & 6 & 4.1 & 4.1 .2 & 4.1 .2 \\
\hline 185 & & & & 6 & $4.1 / 4.2$ & $4.1 .4 / 4.2 .3$ & $4.1 .4 \times 4.2 .3$ \\
\hline 196 & & & & 6 & $4.1 / 4.2$ & $4.1 .4 / 4.2 .3$ & $4.1 .4 \times 4.2 .3$ \\
\hline 13 & & & & 6 & 4.1 & 4.1 .2 & 4.1 .2 \\
\hline
\end{tabular}


Table 1. Cont.

\begin{tabular}{|c|c|c|c|c|c|c|c|}
\hline $\begin{array}{l}\text { Accession } \\
\text { Number }\end{array}$ & $\begin{array}{c}\text { Plant Labels } \\
\text { (Only 1-2 Boxes } \\
\text { Means Informal } \\
\text { Label, } 3 \text { Boxes } \\
\text { Means 'Officially' } \\
\text { Labeled) }\end{array}$ & $\begin{array}{l}\text { Label Assignment to One } \\
\text { of the Parental Species } \\
\text { (Criterium Least 'Pattern } \\
\text { Disturbing' Parent) }\end{array}$ & Perceived Taxa & $\begin{array}{l}\text { Morphotype } \\
\text { (Ward's Group } \\
\text { Ranking) }\end{array}$ & $\begin{array}{l}\text { Cluster } \\
\text { ITS }\end{array}$ & $\begin{array}{c}\text { Subcluster } \\
\text { ITS + } \\
\text { HAPL + } \\
\text { SCOT }\end{array}$ & $\begin{array}{l}\text { Specimen } \\
\text { Unit }\end{array}$ \\
\hline 170 & & & \multirow{3}{*}{$\begin{array}{l}\text { M. suaveolens subsp. insularis or } \\
\text { M. timija }\end{array}$} & 6 & 4.1 & 4.1 .2 & 4.1 .2 \\
\hline 115 & & & & 7 & $4.1 / 4.2$ & 4.1.1/4.2.4 & $4.1 .1 \times 4.2 .4$ \\
\hline 87 & & & & 7 & $4.3 / 3.0$ & - & $4.3 .0 \times 3.0 .0$ \\
\hline 314 & & & & 7 & 2.5 & 2.5 .2 & 2.5 .2 \\
\hline 63 & & & & 7 & 4.1 & 4.1 .1 & 4.1 .1 \\
\hline 200 & & & \multirow{2}{*}{$\begin{array}{c}\text { M. suaveolens (subsp. } \\
\text { suaveolens) or } M . \times \text { rotundifolia }\end{array}$} & 7 & $4.1 / 4.2$ & $4.1 .4 / 4.2 .3$ & $4.1 .4 \times 4.2 .3$ \\
\hline 190 & & & & 7 & 4.2 & 4.2 .2 & 4.2 .2 \\
\hline 76 & & & \multirow{3}{*}{ M. spicata (subsp. spicata) } & 7 & 2.5 & 2.5 .1 & 2.5 .1 \\
\hline 19 & & & & 7 & 4.1 & 4.1 .2 & 4.1 .2 \\
\hline 10 & & & & 7 & 4.1 & 4.1 .3 & 4.1 .3 \\
\hline
\end{tabular}

The ultrametric tree is based on a Bayesian analysis computed with BEAST. The phylogram mentions PP $>0.60$ and main clusters, clusters and subclusters (subclusters based on haploweb, SCoT or a specific sequence combination in ITS). For currently existing taxonomic units, the window of speciation is shown. Further indicated are accession numbers (italic represents sample identical to the lectotype of $M$. spicata L.; bold covers samples with morphometrics, '!' if included in DA; color refers to geographic origin for wild taxa: (a) Western Europe (blue), (b) Mediterranean area to Middle East including North Africa (green), (c) Eastern Europe to Eurasiatic (red), (d) Asia and South Africa (white), (e) unknown (black)), C1/C2, meaning different accessions with exactly the same sequence; morphocloud code; (new) taxonomic identity (provisional); and plant labels, with $\mathrm{C} 1 / \mathrm{C} 2$ accessions in the margin (colored rectangles; for an extended list, see Table S1).

'Taxonomic affinity' links names to sequence clusters: cluster $\mathrm{O}, M$. arvensis- $M$. canadensis; cluster 1, unknown Spicate mint species phylogenetically related to the species in cluster O; cluster 2, M. spicata s.s. and five different related species; cluster 3, an unknown cluster looking somewhat similar to M. longifolia s.s. but perhaps composed of mostly complex hybrid genomes; cluster 4, M. longifolia and M. suaveolens (different subspecies) plus $M$. suaveolens subsp. timija (' $\mathrm{T}$ '); cluster R, M. aquatica (and hybrids such as $M . \times$ dumetorum belonging to $\mathrm{R}$ [aquatica ?]). Unknown taxa or complex hybrid branches are marked with '?'; i.e., this points to the presence of separate taxa that are either new taxa or taxa that might have (had) a historical name but that we do not know for sure (which one) so we do not consider as appropriate to mention.

The first phylogenetic division splits the sequences into two groups, one encompassing main clusters $\mathrm{O}$ and 1 and another encompassing all other samples (Figure 1). The main cluster $\mathrm{O}(\mathrm{PP}=0.99)$ groups sequences from $M$. arvensis L., M. canadensis $\mathrm{L}$. and $M . \times$ gracilis Sole $(M . \times$ gentilis L.; Figure 1). These taxa have traditionally been classified in the taxonomic subsection 'Verticillatae' [22].

The main cluster $1(\mathrm{PP}=1.00)$ encompasses a distinct group of sequences amplified from samples belonging to the classic phylogenetic subsection 'Spicatae' (Figure 1). These sequences are also found on an isolated branch in the haploweb (Figure 2). Most other samples traditionally grouped among the Spicate mints are found in the main clusters 2-4 (Figure 1). Basal to the main clusters 3-4 and to the main clusters 2-4 there are two groups of samples (' $R$ ') that are taxonomically recognized as $M$. aquatica or its hybrids $M$. $\times$ piperita or $M . \times$ dumetorum, which traditionally belong to the phylogenetic subsection 'Capitatae' [22] (Figure 1; Table 1). 


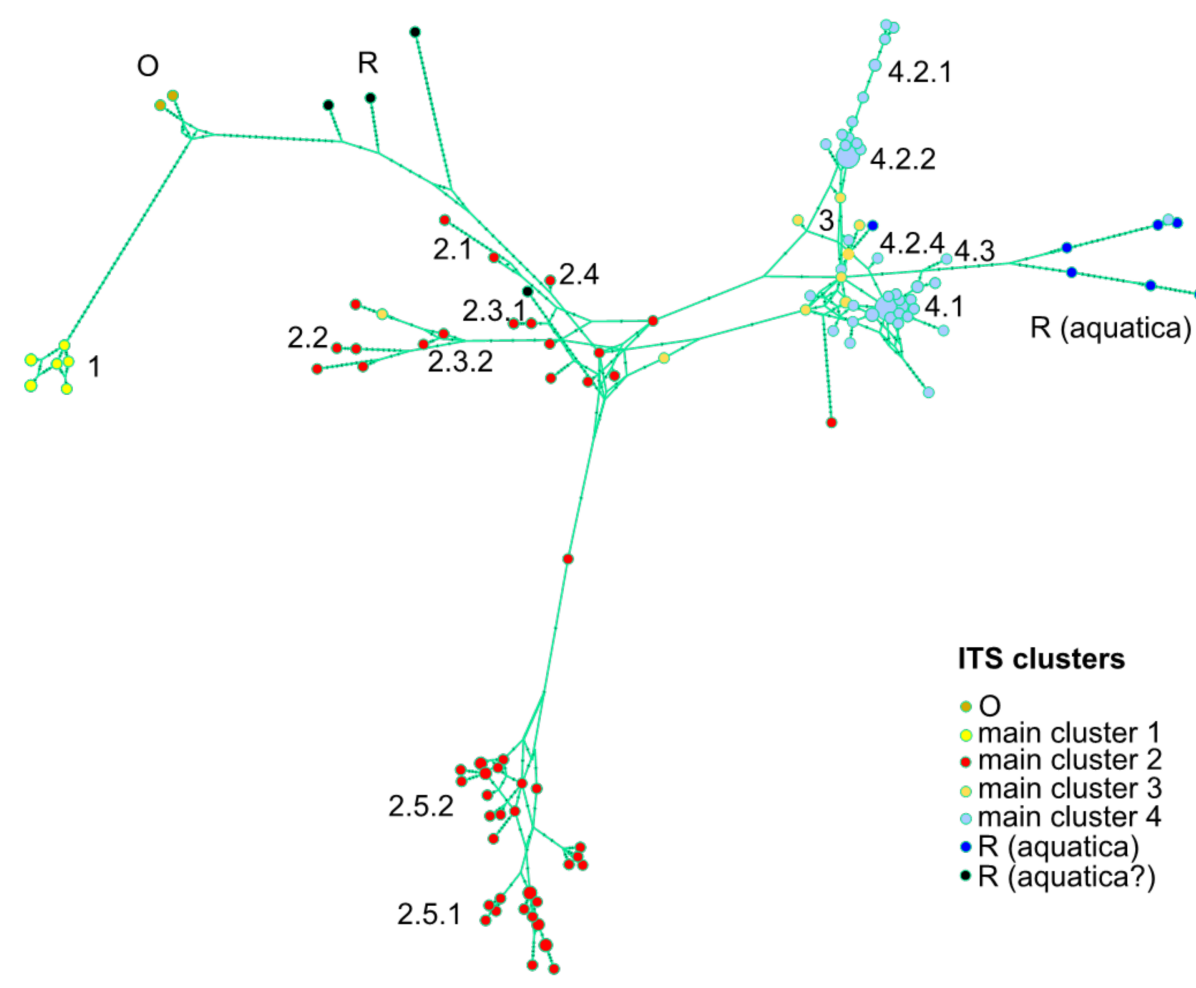

Figure 2. Haplotype network. Subcluster codes indicated next to their corresponding fields for recombinations. Colors according to ITS main clusters. Small black points indicate number of mutations compared to the closest sequence.

The phylogenetic main cluster 2 contains sequences amplified from a diverse set of plants with labels including $M$. spicata, $M$. longifolia and $M . \times$ piperita (Table 1), and it can be further divided into five clusters (2.1-2.5; Figure 1). While labels of $M$. longifolia are also present, most specimens labeled M. spicata or M. $\times$ piperita found in this part of the phylogeny are monophyletic (2.5; Figure 1, Table 1$)$, and here we define this as M. spicata sensu strictu. Using the haploweb, it is possible to further distinguish subclusters 2.3.1 and 2.3.2, corresponding to what is known as M. longifolia subsp. hymalaiensis (Briq.) Briq. and M. longifolia subsp. capensis (Thunb.) Briq, respectively, as well as subclusters 2.5.1 and 2.5.2 (Figure 2). Many of the sequences amplified from samples labeled as the hybrid M. $\times$ piperita are closely related to sequences from M. spicata s.s., in particular to those in subcluster 2.5.2 (Figures 1 and 2), which might suggest a specific M. spicata s.s. lineage as one of the parents.

Main clusters 3 and 4 contain sequences amplified from a large range of taxonomically recognized species (Figure 1, Table 1). Samples found in cluster 3 morphologically resemble M. longifolia s.s. Sequences from this cluster are spread out across the haploweb, indicating a heterogeneous mix with hybrid properties (Figure 2). Although the relationships among the sequences within cluster 4 are mostly unsupported, some subclusters can be recognized (Figure 1). Cluster 4.1 contains genetically very similar sequences amplified from samples mostly labeled as M. longifolia, $M . \times$ rotundifolia, $M$. spicata and $M . \times$ villosa (Figures 1 and 2). These sequences are highly similar to those amplified from an analog to the type specimen of M. spicata L. (sample 540; Figures 1 and 2). Here, we identify this cluster as M. longifolia (L.) L. s.s., including subsp. typhoides Harley and subsp. longifolia with relatives.

Cluster 4.2 encompasses sequences amplified from samples labeled $M$. suaveolens, $M$. $\times$ rotundifolia, $M \times$ villosa and $M$. spicata (Figure 1, Table 1 ). This cluster is here identified as $M$. suaveolens and hybrids with $M$. suaveolens. Hence, some plants formerly labeled as $M . \times$ villosa or M. spicata (or sometimes even as $M . \times$ cordifolia) group with $M$. suaveolens s.l. Clade 4.2 is further split in the haploweb, with subcluster 4.2.2 corresponding to M. suaveolens subsp. suaveolens and subcluster 4.2.3 corresponding to M. suaveolens subsp. insularis 
(Figure 2). Sequences from sample 515, historically once referred to as $M . \times$ billotiana Déségl. \& Durand, are included in subcluster 4.2.1, which mostly contains sequences from plants labeled $M . \times$ villosa or M. spicata (Figures 1 and 2). Sequences from sample 286, a hybrid taxon known as 'Moroccan mint' (M. spicata var. crispa 'Moroccan', M. $\times$ villosa Huds. [51] or M. spicata/M. crispa), are found in subclusters 4.2.1 (M. billotiana) and 4.2.2 (M. suaveolens subsp. suaveolens; Figure 2). The single sample representing M. suaveolens subsp. timija (cluster 4.3) is found basal to cluster 4.2 (Figure 1; Table 1).

Sequences amplified from samples here identified as the hybrid $M . \times$ rotundifolia are found in two phylogenetic positions (Figure 1) as well as in two positions in the haploweb (Figure 2). These sequences are found in clusters 4.1, together with sequences amplified from $M$. longifolia, and 4.2.2, together with sequences amplified from $M$. suaveolens subsp. suaveolens (Figures 1 and 2), which is consistent with $M . \times$ rotundifolia being a hybrid between M. longifolia (s.s.) and M. suaveolens.

In general, main cluster 2 can be recognized as the ' $M$. spicata s.s. complex', whereas main clusters 3 and 4 can be considered to represent the ' $M$. longifolia s.s.-suaveolens complex'. Although M. arvensis, M. canadensis and M. aquatica can be considered as outgroups to the Spicate mints, we found that some of the sequences amplified from these species do indeed cluster within the Spicate mints; this shows that based on ITS sequencing, there is no exclusive division between formerly defined phylogenetic subsections sensu Briquet [22].

\subsection{Start Codon Targeted Polymorphism Technique Integrated with ITS Sequences}

The results from the SCOT analysis varied between markers; six markers (MPST2, MPST11, MPST14, MPST16, MPST18 and MPST30) presented amplifications for all samples, whereas four markers (MPST12, MPST13, MPST17 and MPST27) amplified only from a subset of samples. The absence of amplification is probably due to a lack of a particular marker, but primer site mutations cannot be ruled out.

The first PCF axis $\left(\lambda_{1}=21.83 ; \sigma_{1}^{2}=68.2 \%\right)$ separates samples in subclusters 2.3.1, 2.4 and 2.5.2 from all other samples (Figure 3$)$. The second dimension $\left(\lambda_{2}=7.36 ; \sigma_{2}{ }^{2}=24.8 \%\right.$ ) then separates samples in the subclusters 3 and 4.1 (M. longifolia s.s.) from those of 4.2 .2 ( $M$. suaveolens subsp. suaveolens). Samples recognized as the hybrid $M . \times$ rotundifolia $(4.1 .4 \times$ 4.2.3) are found between or intermingled with the two parental species M. longifolia (4.1) and $M$. suaveolens (4.2.2; Figures 1 and 3). This taxon includes some samples traditionally labeled as $M . \times$ villosa var. alopecuroides (Hull) Briq., that consequently should be changed into $M . \times$ rotundifolia nothovar. alopecuroides. Nevertheless, $M . \times$ rotundifolia is considered as a separate unit here $(4.1 .4 \times 4.2 .3)$.

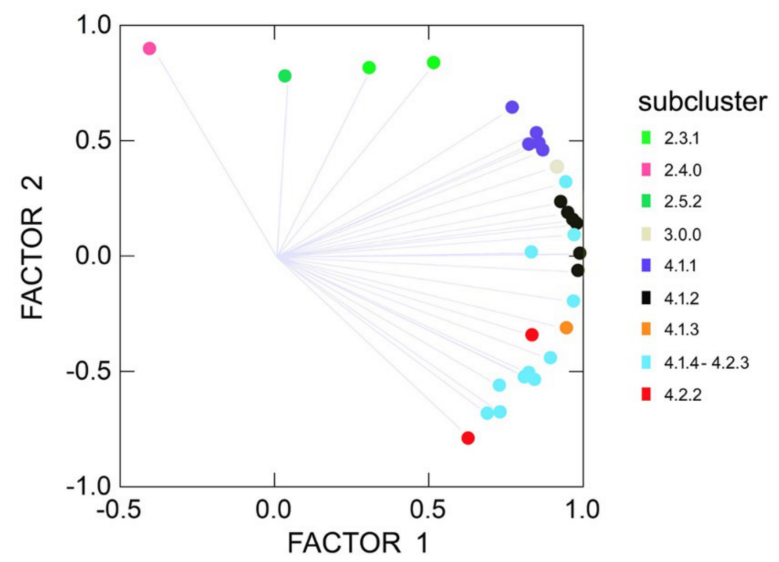

Figure 3. Plot of double factorized SCoT-ITS distances. Subcluster codes are indicated (for explanation, see text).

The SCOT analysis further revealed three clear groups of individuals within the phylogenetic cluster 4.1 (M. longifolia complex s.s.), subclusters 4.1.1, 4.1.2 and 4.1.3. The first two subclusters correspond to M. longifolia L. subsp. longifolia and the related $M$. 
longifolia subsp. nemorosa (Willd.) Wimm. \& Grab./M. nemorosa Willd., respectively. Confusingly, samples found in subcluster 4.1 .3 are traditionally typically labeled as $M$. spicata L. subsp. spicata.

Combining the results of the phylogenetic, haploweb and SCoT analyses, a total of 17 genotypic groups of samples is recognized that can be associated with specimen units (Table 1, Table S1).

\subsection{Genetic Distances}

Genetic distances show large differences depending on the specimen units considered (Table 2). The highest $\mathrm{GD}_{\min }$ values are found between specimen units 1.0.0 and 2.2.0 or 4.2.2, and the lowest values are found between 4.1.4 $\times$ 4.2.3 and 4.2.1 (Table 2). There is a clear $\mathrm{GD}_{\min }$ gradient from high to low values in Table 2, pointing to highly related units within the main clusters $3-4$ (low values, distances $\leq 2.5 \%$; see also Figure 1 ). The units 1.0.0, 2.1.0 and 2.2.0 appear to be relatively distinct (high $\mathrm{GD}_{\min }$, distances range from $4.1 \%$ to $18.8 \%$ with few exceptions). The units $2.3 .1,2.3 .2,2.4 .0,2.5 .1$ and 2.5 .2 are intermediate. A conservative estimate reveals at least nine different species plus several subspecies within the Spicate mints.

Table 2. Overview of genetic distances. Measured minimal values for genetic distances $\left(\mathrm{GD}_{\min }\right.$ as \%) between specimen units. No intercluster hybrids are included. For unit 3.0.0, only nonhybrid samples were included. A mean value of average genetic distances between sister species was assessed by the method of Qin et al. [69] and estimated at 3.98\% (95\% confidence interval 3.36-4.59\%). GD $\min$ values are expected by us to be ca. $20 \%$ lower than the average.

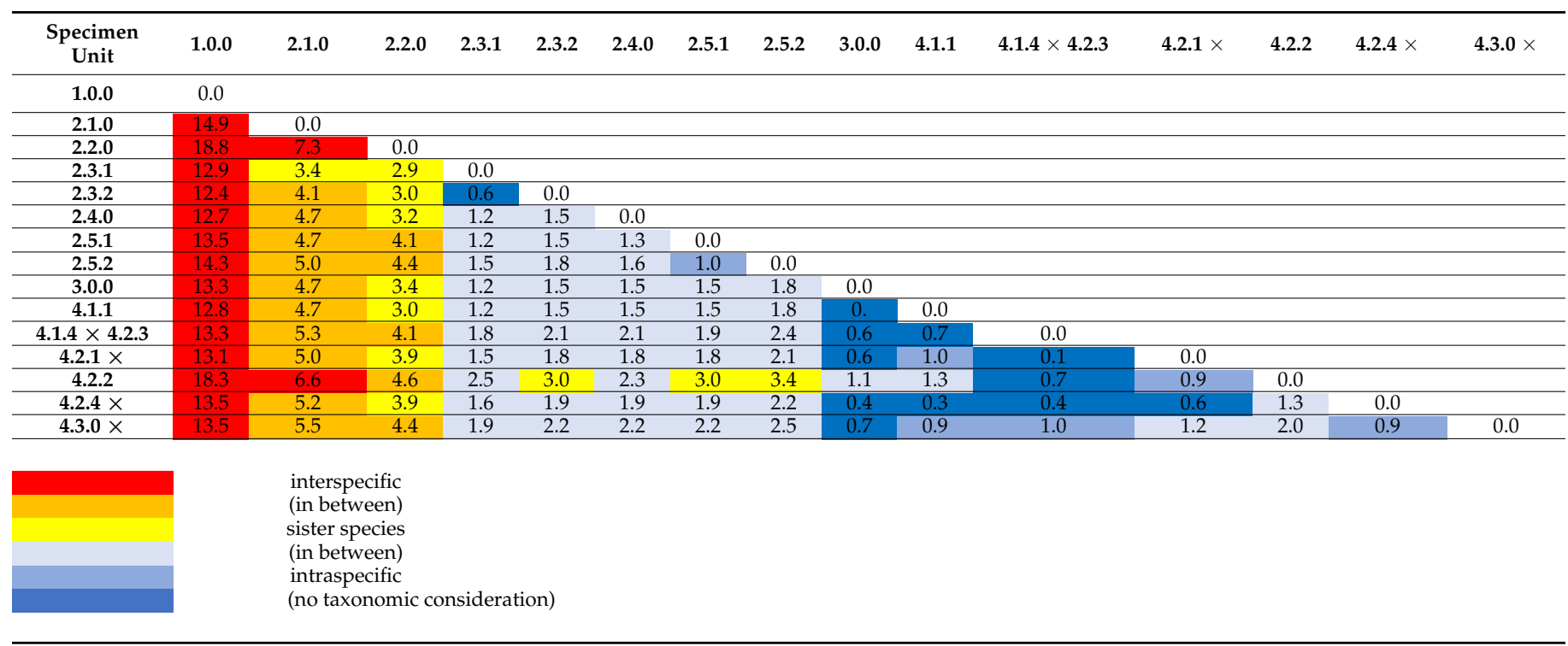

ABGD results (Table S1), including voucher specimens not included in morphological analyses or in the $\mathrm{GD}_{\min }$ crosstable, suggest a potential range of 13-50 species ('groups') within Spicate mints, which is comparable to GMYC estimates $(n=18-51$ including Capitate mints with a minimum of 13 for Spicate mints only). However, these values need to be confirmed using genetic and nongenetic data [70]. The lower limit confirms more or less the presented crosstable results with the exception that, surprisingly, M. longifolia s.s. (4.1) and M. suaveolens (pro parte; 4.2) are not grouped as separate species within the 13-50 species number range. We refer to the 'window of speciation' in Figure 1 for a visualization of the (relative) time frame where the main radiation of today's taxa within sect. Mentha appeared. It is remarkable that a 'final' separation between M. aquatica and the majority of the Spicate mints starts at about the same time as a major radiation within the M. arvensis complex. Meanwhile, the Spicate mints, while mostly relatively young, had already formed some basic complexes, including remote clusters (e.g., 2.1). 


\subsection{Morphological Assessment of Genotypic Units}

\subsubsection{Variable Selection}

The subset of applied variables in Ward's cluster analysis after correcting for multicollinearity is given in Table S2. A total of 21 variables (17.2\%) did not enter Ward's cluster analysis. These variables mainly concern (redundant) calyx variables or common generative features $(n=19)$ and a few vegetative features $(n=4)$.

In DA, the preselection with lasso penalization (controlling for multicollinearity) was evaluated to be more fruitful with glmnet selection $\left(\lambda=0.98\right.$ : axis $s_{1}$ dispersion $=57.5 \%$, axis $_{1-3}$ cumulative dispersion $=84.9 \%$, Stewart-Love ${ }_{1-6}=32.3 \%, \mathrm{R}^{2}=72.9 \%$ ) compared to penalized LDA selection $\left(\lambda=0.20\right.$ : axis ${ }_{1}$ dispersion $=40.9 \%$, axis ${ }_{1-3}$ cumulative dispersion $=$ $91.7 \%$, Stewart-Love $1-6=31.6 \%, R^{2}=63.4 \%$ ) because of a (slightly) higher representativity, great between-unit dispersion already at the main axis (although cumulatively over the dimensions a bit lower) and a strong systematic relationship over the genotypic units. The suitable $\lambda$-value was determined between the minimum and the minimal error value. This resulted in the best set of six variables $\left(n_{\min }\right)$ that are equally divided among generative and vegetative features (Table S2): floral asymmetry (Figure 4) and flower color $(n=3)$, and leaf and stem features $(n=3)$.

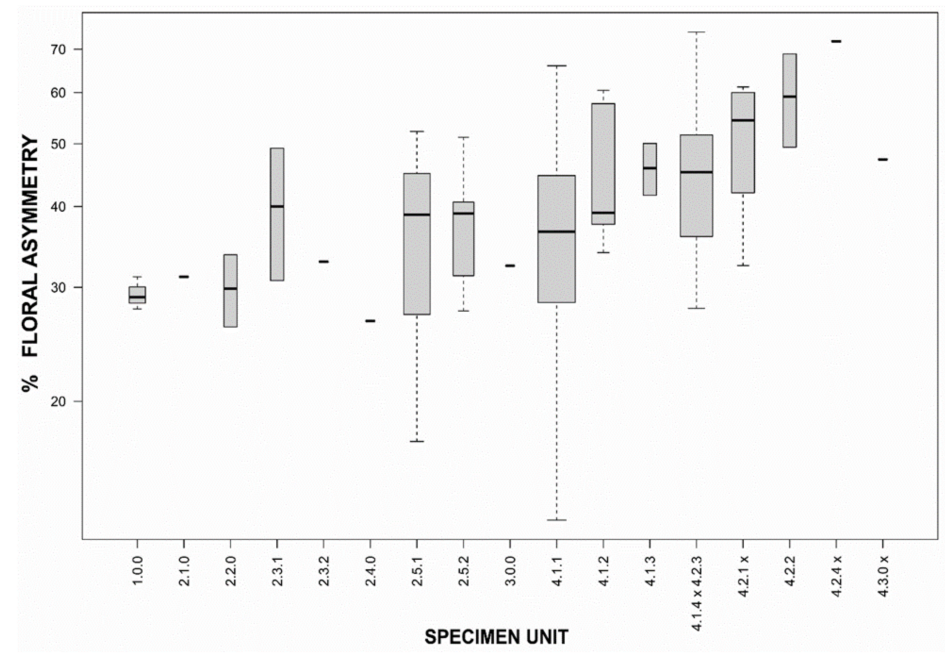

Figure 4. Boxplot: degree of floral asymmetry per specimen unit. Plot indicating the percentage asymmetry (the combination of the variables numbered as 27 and 32; Table S2) observed in flowers belonging to each of the studied genotypic units.

\subsubsection{Unconstrained Morphology}

A total of seven morphological Ward's groups were identified by phenetic analysis (Table 1). Discriminant analysis (DA) was then performed on the 17 genotypic specimen units, and Ward's groups were plotted (Figure S1). There is a limited association $(\lambda=0.30)$ between the Ward's groups and the specimen units and only a partial significance between the Ward's groups and the two most important DA axes (Kruskal-Wallis $p_{1}=0.000$, $p_{2}=0.394$ ). This indicates that the Ward's projected groups (morphotypes; Figure S1) harbor high genetic heterogeneity and show only partial and limited correspondence to the genotypically induced DA-space (with a distinction along the first axis suggesting a primarily one-dimensional, hence one-sided, interpretation in terms of morphology; see below). There is, however, a very obvious correspondence between the unconstrained morphological Ward's groups and the plant labels (Table 1), which is somewhat expected given that mint taxonomy is currently largely based on morphology. Thus, traditionally groups are (superficially) perceived as (1) M. spicata (subsp. glabrata) or as $M . \times$ cordifolia; (2(-1)) M. longifolia including M. asiatica, M. longifolia subsp. hymalaiensis, M. longifolia subsp. capensis; (3(-2)) M. longifolia or M. spicata subsp. tomentosa/subsp. condensata/M. microphylla; (4) M. longifolia or hybrid; (4-5) M. spicata subsp. spicata or M. $\times$ villosa; (6) M. 
suaveolens (subsp. suaveolens) or its hybrids, including $M . \times$ villosa (subsp. alopecuroides) and $M . \times$ rotundifolia; (7a) M. suaveolens subsp. insularis or M. timija plus M. suaveolens (subsp. suavolens) or $M . \times$ rotundifolia; and (7b) M. spicata (subsp. spicata). The genetic heterogeneity within these Ward's groups is clear from Table 1 when inspecting the genetic (sub)clusters.

\subsubsection{Constrained Morphology}

The Stewart-Love canonical redundancy index equals 0.323 when based on the first six dimensions of the constrained DA-space as well as the full morphospace (a PCF with a cumulative six-dimensional variance of $46.0 \%$ of the total morphological variation). This implies that $32.3 \%$ of the generic signals of the full morphospace are explained by the variation among the specimen units in the reduced (constrained) morphospace. However, $96.3 \%\left(\Delta_{W}=0.037, p<0.001\right)$ of the between-group morphospace dispersion among the 17 genotypically defined specimen units is explained by the six significant morphological variables (Figures 5 and 6, Table S2).
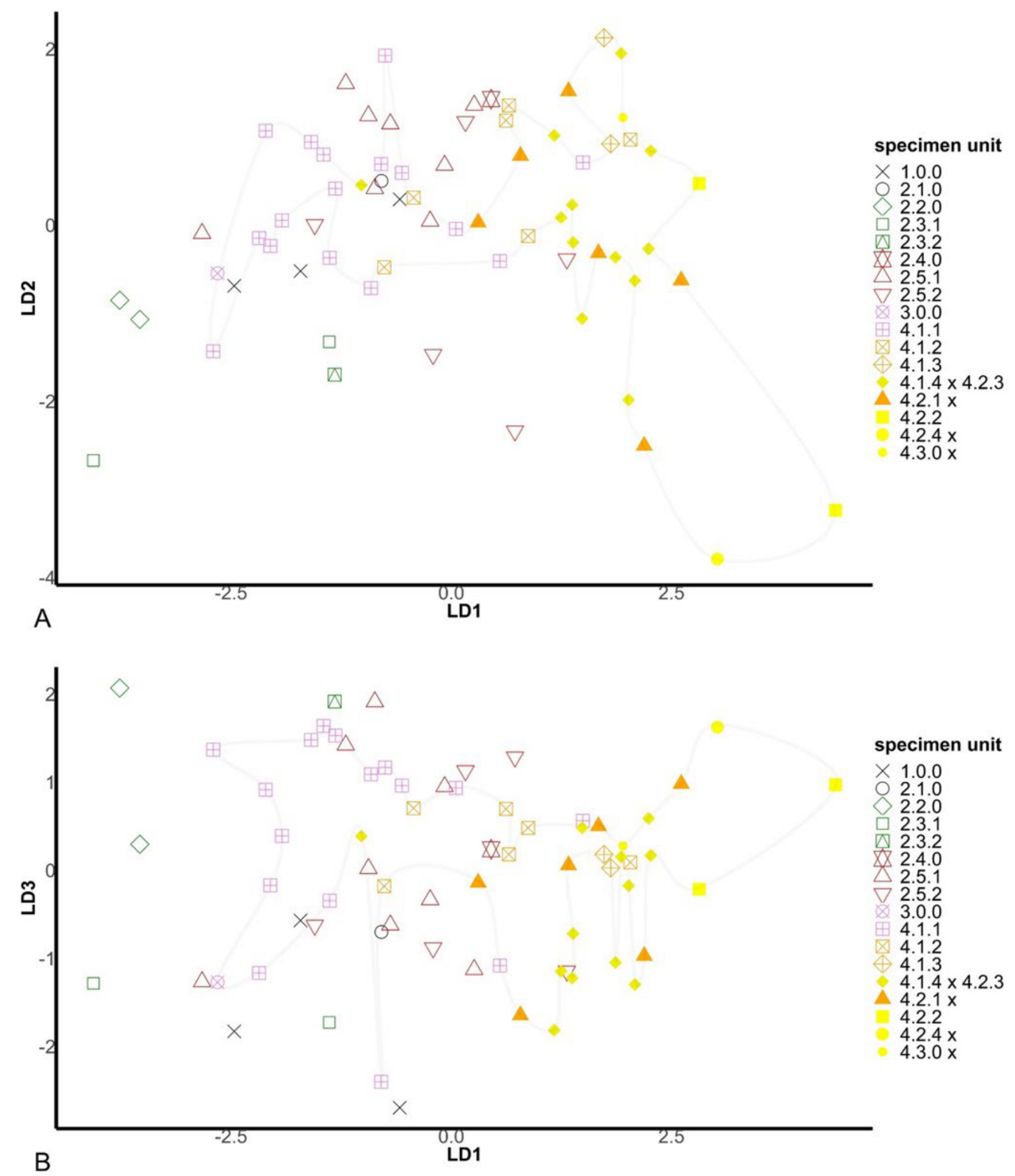

Figure 5. Discriminant analysis relating ITS-based genotype to specimen units. Symbols and colors according to genotypic specimen units (based on observed genotypes). Light grey polygons are manually drawn to indicate the outer perimeter of the Mentha longifolia s.s.-Mentha suaveolens complex, as a central core within the Mentha spicata s.s. complex (outer shell). (A) DA1-2. (B) DA1-3. 


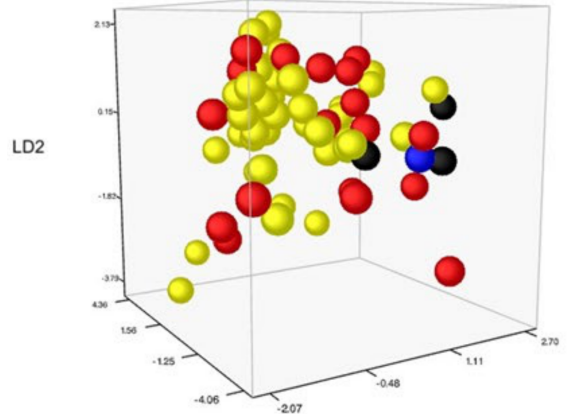

LD1

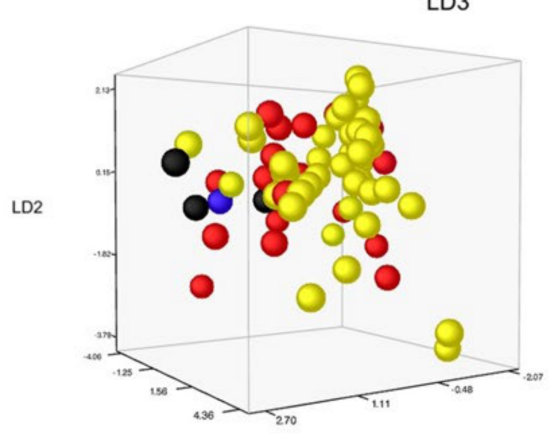

LD1

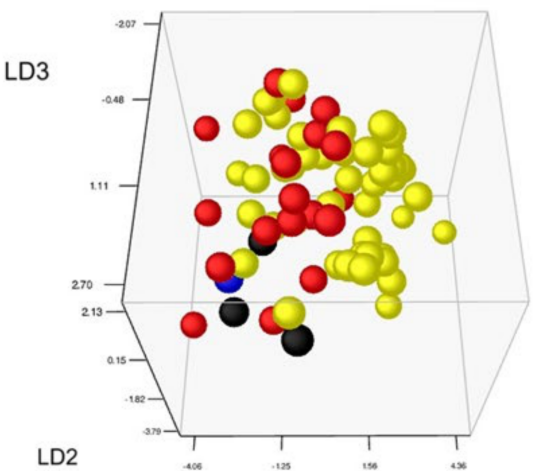

LD1

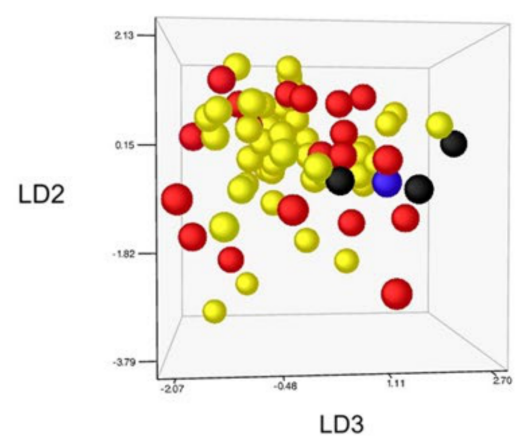

LD1

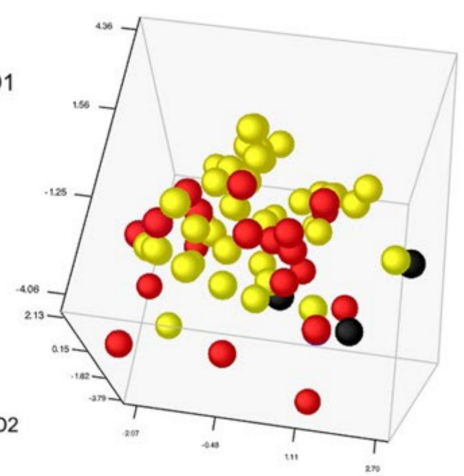

LD3

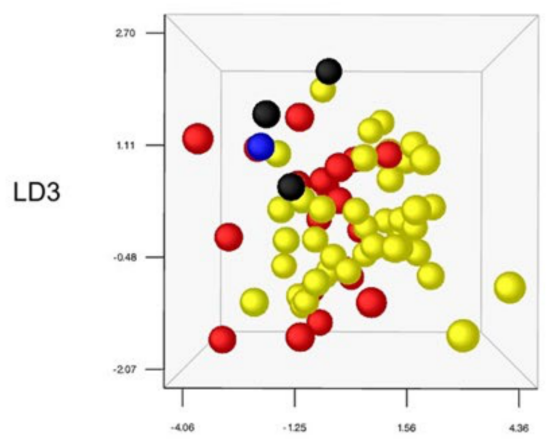

LD1

Figure 6. Discriminant analysis visualizing the general morphocloud pattern. Discriminant analysis results with 3D pattern reflecting general relationships between main groups. The inner core-outer envelope shows how the M. longifolia s.s.-suaveolens complex and the M. spicata complex, respectively, are mutually connected and at the same time also largely separated. The outer envelope contains accessions with sequences belonging to main clusters 1 (black) and 2 (red), while the inner core has sequences belonging to main cluster 4 (yellow). Note that the only morphologically analyzed accession with sequences from main cluster 3 (blue) is ordinated at the outer edge.

What has historically been perceived as M. longifolia (s.1.) (cf. Figure 1, clusters 2.1, 2.2, 2.3 and 2.4) is found on the negative side of the first axis, and the classic M. spicata (s.1.) (including $M . \times$ villosa) is mostly found at the positive side of the first axis (Figure 7A). However, M. spicata s.s. as defined here (cf. cluster 2.5) is mainly situated central on the first axis, bordering and partly intermingling with M. longifolia s.s. (4.1.1, 4.1.2; Figure 6A). Importantly, DA demonstrates (Figures 5 and 6 ) an emerging pattern among the specimen units that gives the impression of an 'inner core' of the M. longifolia s.s. - suaveolens complex and an 'outer envelope' of M. spicata s.s. with relatives and unit 1.0.0. It shows that there is only limited morphological overlap between accessions with sequences belonging to the different main phylogenetic clusters (Figure 6). This is even more clear after DAmorphocloud clustering (Figure 1 and Figure S2). This cluster analysis result contains a 
very limited number of 'aberrant classifications', i.e., accessions genetically belonging to one main cluster but morphologically to another main cluster $(2.8 \%$ are aberrant when excluding $7.1 \%$ borderline cases and 7.1\% M. spicata s.s. 'look-alikes' that are actually $M$. longifolia s.s. residing in the 'inner core' morphocloud; Figure 5). Some of the accessions $(12.9 \%)$ do, however, occur in mixed morphoclouds where plants from the M. spicata s.s. complex morphologically resemble plants of the M. longifolia s.s.-suaveolens complex. Hence, a total proportion of $84.3 \%$ of the analyzed accessions show a morphology that is unambiguous with respect to their phylogenetic relationships.

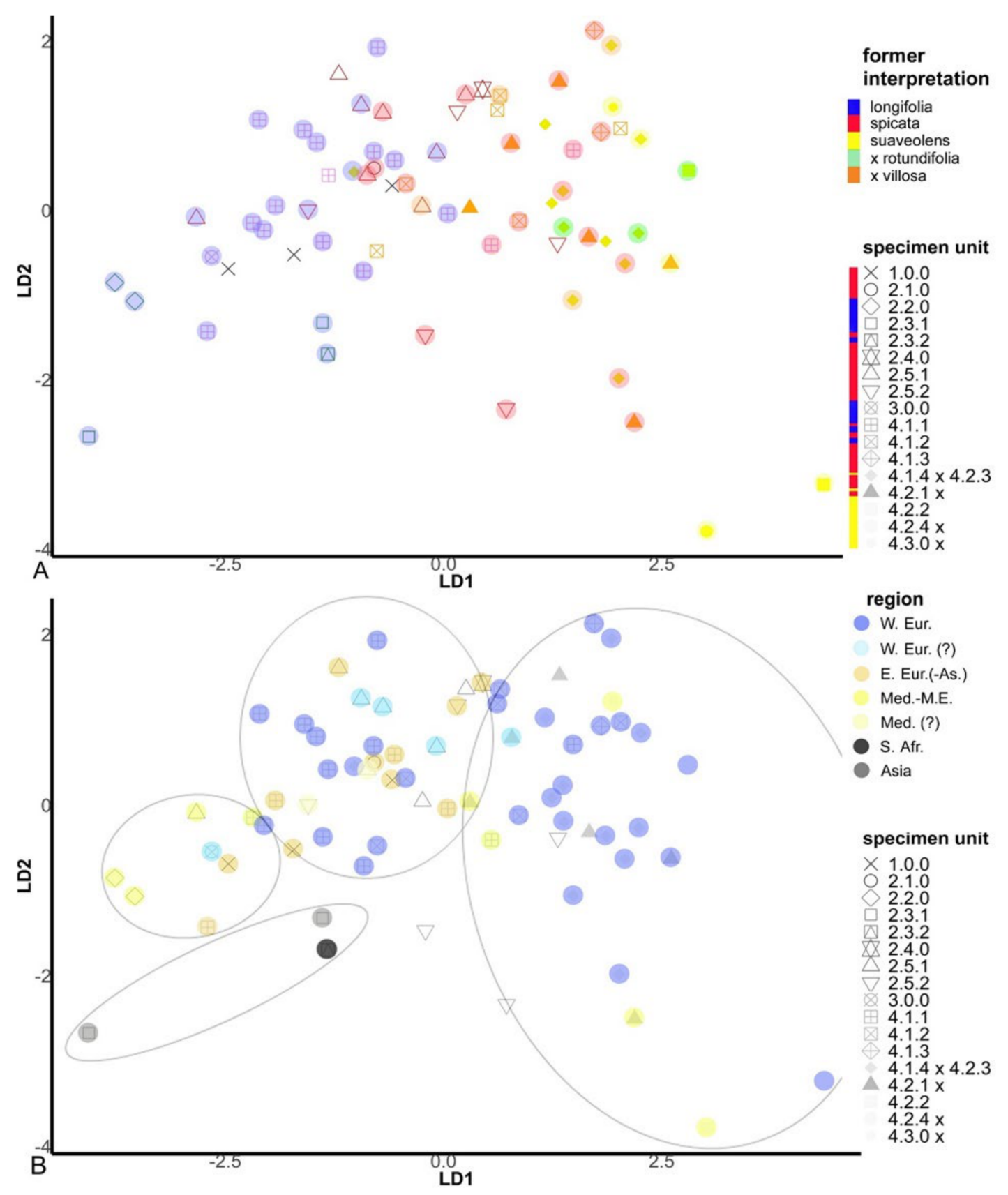

Figure 7. Species perceptions and mint biogeographical origin plotted on discriminant analysis results. Exogene data plotted on existing discriminant analysis. Symbols according to genotypic specimen units. (A) Former species interpretation plotted on DA1-2. Colors represent 'classic' species (based on plant labels). (B) Mint biogeographical regions plotted on DA1-2: (a) Western Europe; (b) Mediterranean area to Middle East, including North Africa; (c) Eastern Europe (to Eurasiatic); (d) Asia; (e) South Africa. Colors represent different regions of origin from the wild gene source. Symbols in grey (no color) are cultivated or introduced taxa without known origin/location. Ellipses are arbitrary as manually added. 
Interestingly, the first two axes of the DA plot also reflect a morphological distinction between West European and Mediterranean (including Northwest African) $M$. suaveolens and associates (units 4.2(.1-2)/4.2.4 $\times$ and 4.3 including hybrids) and the geographically more remote mints from Asia and South Africa (units 2.2 and 2.3(.1-2); Figures 1 and 7B; Table S1). At the extreme, Southeast European and Eurasiatic mints form a cloud (Figure 7B). All other mints, however different from each other but usually pan-European, are squeezed in between (Figure 7B). Mints originating mostly from other continents outside direct European influence $(2.3 .1,2.3 .2)$ and some Southeastern European mints $(2.1 .0,2.2 .0)$ are unfolded in the DA1-3 plane but barely intermingle with $M$. longifolia s.s. or with other taxa except Eurasiatic mints (1.0.0; Figure 7B).

\section{Discussion}

\subsection{A Revised Phylogeny}

Here, we present an inter- and intraspecific evaluation of both genotype (ITS + SCoT) and phenotype within the genus Mentha, resulting in a revised phylogeny of the Spicate mints. To our knowledge, this evaluation is the most comprehensive of its kind. Our findings suggest that the Spicate mints are polyphyletic (main clusters 1-4, Figure 1) and much more diverse than previously thought. The obtained ITS GD values suggest at least nine species among the analyzed samples (Table 2), an estimate that is supported by the lower limit $(n=13)$ of the ABGD/GMYC analyses. However, the upper limits of the ABGD/GMYC analyses including vouchers suggest a large number of hidden (cryptic) species. Indeed, we were able to identify several cryptic taxa, e.g., M. nemorosa or $M$. billotiana, and diverse unnamed taxa (Figures 1 and 2). While most of the traditional Spicate mints appear polyphyletic, we find a number of ITS clusters that can be interpreted as (redefined) M. spicata s.s., M. longifolia s.s. and M. suaveolens s.l. (Figure 1). Obviously, the distinguished genetic subclusters globally correspond to a set of recognizable phenotypes described by a low number of relevant variables (e.g., Figure 4). In summary, we present a fundamentally different phylogeny compared to previous publications, with totally remote Spicate mint taxa and a basal split between M. spicata s.s. and M. longifolia s.s., also questioning the identity of the lectotype of $M$. spicata.

The DA results offer a nice arrangement of genotypic units sorted along principal dimensions, pointing to a substantively strong correspondence between the modeled morphology and the genetic groups at a higher taxonomic level (Figure 6). The overwhelmingly consistent inner core-outer envelope pattern emerged irrespective of the imposed genotypic structure, which highlights the relevance of the selected morphological variables regardless of technical and statistical qualities in a model context that initially led to the (penalized) selection. Therefore it is probably no coincidence that exactly highly relevant morphological features at genus or family level such as floral asymmetry (Table S2, Figure 4) show systematic and meaningfully structured differences for varying genotypic groups. Hedge [71] pointed to Mentha as an example of evolutionary trends in the Lamiaceae family, not in the least concerning floral asymmetry (actinomorphic versus zygomorphic flowers). Traits such as floral asymmetry and varying patterns of oil glands are possibly involved in insect-flower coevolution [72-76], and such traits are likely to be important for speciation. Some of the selected leaf characteristics (such as petiole and venation; Table S2) also have ecological relevance, for example, in response to varying humidity levels in the atmosphere and soil or in relation to herbivory (e.g., [77]), and are linked to differential adaptation (e.g., [78,79]). The genetic and morphological distinctions between the species are further supported by obvious biogeographic differences between the taxa (Figure 7B).

As is discussed in the following, the current mint phylogeny still looks too much like a hotchpot; it straitjackets Spicate mints by their three recognized classic species, thereby dumping idiosyncrasies in a bottomless hybrid container. The Ward's groups we present offer, via morpho-typology (Table 1), a plausible explanation for the classic taxonomic assignments within Mentha. However, as many of the traditionally defined taxonomic units are polyphyletic, a revised taxonomy taking into consideration both morphology and 
genetics is needed. Here we present a much-refined phylogeny with recognizable groups of samples that are also morphologically similar. In particular, we show that the Spicate mint phylogeny is characterized by polyphyly of previously recognized species and that its diversity is much higher than formerly conceived. This shows that much more intensive sampling is needed to fully understand the diversity gradients, elucidate cryptic taxa and define new taxa in Mentha. We also demonstrate that phylogenetically defined groups in this hyperdiverse genus can also be morphologically distinguished. Nevertheless, more research on, e.g., microstructures or ontogenetic features, not assessed here, might help in further elucidating phylogenetic relationships among the Spicate and Capitate mints. However, we do note that the morphospaces of many classical taxonomic units of Spicate mints are largely overlapping. Hence, taxonomic identification solely based on morphology is likely to remain problematic.

\subsection{Former Phylogenies in the Light of New Results}

Over the last couple of decades, there have been numerous phylogenetic studies of the genus Mentha, mostly of the section Mentha, using morphological, cytological and chemical characters (e.g., [59,62,63,80-91]) as well as molecular markers (e.g., [55,60,61,64,66,92-105]). However, despite the enormous amount of data gathered, the classic taxonomic divisions (e.g., [22,106]) still largely stand. Studies describing an integral phylogeny of the whole genus using molecular markers concluded that the Spicate mints are monophyletic $[33,93,107]$. However, most studies (but see $[55,66])$ have only investigated a limited number of species and/or individuals, largely ignoring inter- and intraspecific variation or discarding the taxonomical implications it has. Moreover, integrated genotypephenotype analyses are not frequent, and often an insufficient number of genetic markers are used, or the morphological descriptors are scarce (but see [32,65]).

Molecular phylogenetic and phenetic studies have become most popular in the last two decennia and are mostly based on sequencing information (nrDNA or cpDNA) or on different marker methods (e.g., RAPD, ISSR and SCoT). An important phylogeny of the whole genus is, however, based on morphological data [33], and at least for sect. Mentha, the classic species remain: $M$. longifolia clusters together with $M$. spicata and is consecutively related to M. suaveolens (a generalized comparative scheme is given in Figure S3). Those taxa are considered as a tight monophyletic (Spicate mint) complex most closely related to $M$. aquatica and more distantly related to $M$. arvensis. Similar results have also been derived by different molecular techniques (for typical examples, see [108]), but also several different dissonant phylogenies exist as discussed further. However, the classic species (names) are not questioned, as they are always recycled. As a result, dissonance might be just an artifact of Babylonian labeling. Hence, diving into published Spicate mint phylogenetics, it is unfortunately hard to determine the difference between labeling effects and (true) genetic differences for certain when sequence data are scarce or unavailable. Gobert et al. [55] assessed relationships (by AFLP-based molecular marker technique) within sect. Mentha using many Spicate mints and concluded, at least as far as nrDNA data are considered, that M. spicata is intermediate between M. suaveolens and M. longifolia, with M. aquatica and M. arvensis together as a separate clade. According to Bunsawatt et al. [93] (ITS), M. suaveolens and sister species M. spicata form one single clade with M. longifolia and a 'strain' of $M$. canadensis (supposed to be a tertiary relict amphidiploid descending from M. longifolia $\times$ arvensis [109]), while $M$. aquatica forms a different clade, as does $M$. arvensis (with another strain of $M$. canadensis).

Gobert et al. [66] returned with a more elaborated ITS phylogeny (with accompanying cpDNA phylogeny) that has a basic resemblance to our phylogeny; however, due to the presence of confusing labels and different tree swapping, the molecular response looks quite noisy and the interpretation is very different (and polyphyletic) [66]. Moreover, the phylogeny contradicts former research results or at least suggests profound changes [55]. Although the name $M$. spicata is overly represented, the authors only included just one (two?) M. spicata s.s. plants (as defined here), which turns any direct interpretation of 
the tree into a nontrivial exercise [66]. To make things clear, we reanalyzed a number of their voucher sequences [66] (Figure 1 and Figure S3, Table S1), making a comparison with our results possible. Our phylogeny (Figure 1) is much more extended because of a higher sample size, with different remote groups, and our interpretation is very different. Nevertheless, the dendrogram given by Gobert et al. [66] reflects some but not all of the basic splits presented by us: the split between $M$. arvensis, followed by $M$. aquatica and finally the separation of the M. spicata complex from the M. suaveolenslongifolia complex, although Gobert et al. [66] did not interpret it that way. Using cpDNA (trnL-trnF), Bunsawatt et al. [93] concluded that 'the seven species' from sect. Mentha are not monophyletic. M. aquatica and $M$. arvensis (with $M$. canadensis and the associated $M$. japonica) form one clade (Figure S4) beside M. suaveolens on the one hand and M. longifolia with M. spicata on the other hand. According to Bunsawatt et al. [93], the sister group relationship of the latter two species suggests that $M$. longifolia, rather than M. suaveolens, is the maternal parent of $M$. spicata (as the $\operatorname{trnL}-\operatorname{trnF}$ region is presumably maternally inherited). Interestingly, the considered ' $M$. longifolia' is, however, voucher specimen $564(\mathrm{~V})$ (Figure 1) that is grouped in our phylogeny under cluster 2.2 (which is related to cluster 2.5, M. spicata s.s.; Figure S4). Thus, a low sample size is probably another reason why the historic interpretations of derived phylogenies remained ambiguous. Even the cpDNA phylogeny of Gobert et al. [66] is plagued by a lack of samples, but it still is the largest published cpDNA tree for Spicate mints ever. Most other relevant cpDNA phylogenies $[25,93,97,107]$, as far as Spicate mints concern, more or less fit within the larger cpDNA phylogeny [66] but exceptions exist (see below).

The mentioned cpDNA phylogeny (Figure S4) reflects a series of splits where the highly diverse 'M. aquatica' plays the leading role (present in all the major branches). Although M. aquatica is not commonly interpreted as a hybrid species, it has a high ploidy level (mainly octoploid but also nonaploid [104]), and hence its polyphyly in the ITS-based phylogeny (Figure 1 and Figure S4) can possibly be explained by a high number of gene duplications with different evolutionary histories. The cpDNA phylogeny is, however, not as informative as our ITS phylogeny as the majority of the relationships within the Spicate mints remain unresolved (see also [25]). Contrary to all the former cpDNA results, Thakur [110] puts $M$. arvensis with $M$. spicata next to M. aquatica. We refer to the huge diversity of Spicate mints to interpret such dissonant results. Kalfagianni [67] ( $t r n H-p s b A$ and ITS) points again to strongly heterogeneous results signifying probably high putative intraspecific variability, but possibly due to labeling issues the results may be incomparable and inconclusive. Moreover, the rbcL-based phylogeny by Ahmed [28] is clearly different, which might also be a consequence of sampling (bias).

High intraspecific variability is clear from other molecular studies too (e.g., marker techniques AFLP, RAPD, ISSR and SCoT), which mostly led to very heterogeneous phylogenetic or phenetic results $[32,61,98,104]$. Choupani et al. [111] repeat for Spicate and Capitate mints (M. longifolia, M. spicata, M. aquatica etc.) the remarkable conclusion that intraspecific variability is larger than interspecific variability-a thesis that makes sense in a polyphyletic constellation where cryptic species might hide [40] (see also many other mutually deviant results as for interspecific relationships and variability in Spicate/Capitate mint species $[30,31,60,112-115])$.

As rightly summarized by Soilhi et al. [32], previous studies that combined molecular markers with morphological data found no agreement between the (clustered) results of both molecular and morphological markers separately $[31,61,116]$. Unfortunately, no such nrDNA or cpDNA sequence-based comparisons have been published in the case of Spicate mints. Only very few studies analyzed standardized morphological data with a high number of descriptors as we do (as far as we know, only $[32,117]$, but the last one does not concern Spicate mints). So far researchers studied a very limited number of unstandardized morphological features that, moreover, show high intraindividual and intraspecific variability (e.g., pistil length, stamen length and their ratio), while at the same time genotypes of species (M. spicata-M. longifolia) cannot be separated in cluster results 
based on ISSR molecular markers [112]. The dendrogram presented by Soilhi et al. [32] represents morphotypes that yield, among other findings, a deep split within 'M. spicata', while the molecular data results show very different, totally mixed-up groups (where $M$. longifolia, M. spicata, M. crispa and M. aquatica or $M . \times$ piperita are repeatedly included). Common reasons given for discongruity include the character or genetic marker selections, the complex hybridization histories and phenotypic plasticity [32]. However, the idea of an unsuitable taxonomy and nomenclature never pops up. Although it is clear that there is high intraspecific variability, we suggest that this is partly caused by the historic complex taxonomy and that the classically used plant labels cause much of the current phylogenetic confusion within Mentha. We, therefore, suggest that a revised taxonomy is in order, one that takes both morphological and genetic data into account.

\subsection{Perspectives in Mint Genetics}

\subsubsection{Nuclear DNA versus Chloroplast DNA}

ITS sequences are generally considered to be a relatively good phylogenetic marker to distinguish biological variability for plants [69]. Although several studies suggest that the most accurate phylogenetic reconstructions are obtained when multiple loci are combined, ideally targeting both chloroplast ( $m a t K, n d h F, r b c L, r p s 16$ and $t r n L-F$ ) and nuclear markers (ITS) [118-120], it has been shown in Lamiaceae that one marker (e.g., $\operatorname{trnH}-p s b A$ ) can nicely resolve taxonomy [121]. Nuclear markers on their own appear to be promising tools to disentangle complexes of hybrids such as those found in the genus Mentha. Thus, we generated a global view on the genetic diversity and relationships within Mentha using SCoT in combination with the ITS marker. Some authors have argued that the use of the ITS marker in detecting cryptic species is limited because the evolutionary rate of the ITS region is too slow [122]. This appears to be the case for mints, where indeed supplementary analyses (Figure 2) and markers (Figure 3) are needed to refine clusters of individuals and sequences. Future comparisons should include genetic information from plastid markers, such as $t r n H-p s b A$ and matK. While this may provide a better insight into, for example, relationships between seed and pollen dispersals, plastid marker data on their own will not suffice to generate a full phylogenetic overview given the importance of hybridization and polyploidy in Mentha.

Thus far, cpDNA phylogenies (Figure S4) appear to provide less refined phylogenetic relationships among mints compared to ITS-based phylogenies. However, cpDNA does add information on maternal lines and it does confirm a few of the basal splits also found using ITS data (Figures S3 and S4). The incongruences between evolutionary histories of nuclear and plastid DNA in the subtribe Menthinae are not surprising given the high frequency of interspecific hybridizations [123]. The low genetic differences found between mints using plastid markers $[28,93,97,121,123]$ show that these markers on their own are not as good as nuclear markers to infer interspecific relationships between mints. Bunsawatt et al. [93] explicitly mention that some parts of the trnL-trnF and the ITS phylogenies lack resolution. When comparing the trnL-trnF spacer with ITS1-ITS2 in terms of percentage of variable nucleotide sites [93], the $\operatorname{trnL}-\mathrm{trnF}$ region sequences are found to be about four times less variable ( $12 \%$ versus $47-51 \%)$.

Previous studies have suggested that the ITS sequence might show variation that is less useful to disentangle interspecific relationships [124] or that might confound the relationships between mints [93]. However, here we show that when combined with other markers, such as SCoT and morphology, ITS suffices to disentangle most phylogenetic relationships and that previous Babylonian confusion on phylogenies have been enhanced by the use of plant labels. In contrast, Figure 1 shows how a multidimensional response set of morphological markers is able to propose a meaningful composition that casts light on a complex phylogeny, without the need for any a priori taxonomic classification.

Combining cpDNA and nrDNA would help in future research to uncover both old and recent hybridization or polyploidization events on representative interspecific samples of natural populations, and using single-copy nuclear genes would also help with this en- 
deavor $[125,126]$. However, to unequivocally resolve hybridization history, whole-genome sequencing of multiple individuals is required, and genetic admixture analysis [127] using a large number of single nucleotide polymorphisms (SNPs). Moreover, network-based representations would be more suitable to visualize the reticulate relationships present in mints, while there is a need for detailed population genetic studies based on samples over large biogeographic regions covering the diversity gradients.

\subsubsection{Intraindividual ITS Variability as A Mirror of Intraspecific Variation}

The incongruence of different phylogenetic trees, particularly the differences between cpDNA and nrDNA, may hold in a nonconcerted evolutionary context with effects of recombination, hybridization or incomplete lineage sorting. Therefore, phylogenetic reconstruction of a genus overwhelmed by hybridization and polyploidization, such as Mentha, is challenging. Additional genetic challenges include intraindividual ITS polymorphism (IIP) and pseudogenes [127-129]. IIP is common [130-135] and can be structured in very different ways, but most often the interindividual variability is smaller than IIP variation (e.g., [136]). IIP can be due to, for example, incomplete lineage sorting, divergent and unconcerted paralogs, incomplete concerted evolution after hybridization, pseudogenization following gene duplications or recombination between ITS copies [124,133,134,137], all of which might influence the inferred phylogenetic relationships. In addition, the parentbiased homogenization of ITS following polyploidization or hybridization will affect the inferred phylogenetic tree and, hence, the derived evolutionary relationships. As a consequence, some authors advise against the use of ITS for phylogenetic inferences [137-139]. However, ITS is still a commonly used marker for phylogenetic studies of plants, and even in cases of abundant IIP, it has been shown that this marker is still useful for species identification (e.g., [140]). In 'Better the devil you know?' [141], the use of ITS is further recommended but strong warnings are also given. Thus, handling IIP as an extra source of information in Mentha implies the use of other concepts and, hence, distinct models, which turns IIP into a model challenge instead of a data problem. For instance, IIP can be an interesting tool for uncovering incomplete lineage sorting, introgression, hybridization and reticulation [138]. Indeed, the Bayesian method used here can deliver evidence of past hybridization and reticulate evolution [133]. The higher sequence variability generated by IIP both provides higher interspecific resolution and is associated with a higher intraspecific variability $[140,142,143]$, which can be useful for identifying cryptic species $[144,145]$. The positive correlation between IIP and inter-/intraspecific variability generates patterns from which GMYC-based methods [146] can benefit in detecting cryptic taxa [144]. We also took GMYC principles into account (waiting times as a window of speciation on the ultrametric tree, Figure 1) and used them to support the estimation of species numbers within Spicate mints.

Disentangling alleles or phased sequence variations from nuclear markers using traditional sequencing techniques (i.e., Sanger sequences) often requires cloning, especially for species with high ploidy [147]. For relatively low frequencies of IIP, direct sequencing poses no problem [127], and here we did not find it necessary to use cloning to disentangle intraindividual sequence variants. Indeed, the nrDNA, including the ITS region, is often represented by hundreds of copies that in principle follow concerted evolution. Therefore, no more than one or two sequence types are expected to be observed in each specimen. Although the homogenizing effect of interlocus concerted evolution of paralogs can hide the history of one or more parental genomes in allopolyploids when standard PCR methods are used alone, this is not systematically the case [148]. Here, we find that only a minority of samples $(8 \%)$ showed minor peaks $(<50 \%$ the size of major peaks), and these samples are spread across the phylogeny (Figure 1 and Table S1) without being obviously clustered, except some samples found in main cluster 3 . That clade largely consists of hybrid accessions. Only one sample (626, main clusters 1-2, Figure 1) showed more than two similar-sized peaks (Table S1). Two of the sequences (626c-d; main cluster 1) have a low GC content, which in principle could indicate pseudogenization, although no such cases were 
observed. This particular sample was also removed from the genotype-phenotype analysis. In conclusion, we do not believe that IIP had a negative interference on the presented phylogeny or on the integrated genotype-phenotype analysis. Indeed, in the integrated genotypic-phenotypic analyses, most of the hybrid taxa were not included.

\subsection{Plasticity in Porous Genomes-Future Challenges in Mentha}

The phylogenetic complexity within the genus Mentha mirrors the complications with species concepts in general, especially for taxa with porous genomes where introgression, hybridization and polyploidization have significant evolutionary impacts [18,149-151]. Hybridization and polyploidy have indeed most likely played important roles during speciation in mints, which forms one reason the number of taxonomically valid species is a subject of controversy [152,153]. The complex genomic networks of taxa with porous genomes cause phenotypic mosaics that behave dynamically [154]. Indeed, plasticity is known to be widespread in cryptic taxa such as Mentha (e.g., [155-158]), which confounds morphological identification. However, low levels of plasticity have been reported for $M$. $\times$ verticillata [159]. We cannot totally exclude the effects of plasticity here, but our garden setup would eliminate most of its side effects, including heteroblasty. Furthermore, the unexplained part of the morphological variation is likely linked to genotypic differences between taxonomic units that were not captured by the neutral markers analyzed here. Given the complex evolutionary dynamics of Mentha, including convergence, reticulation, introgression and incomplete lineage sorting (e.g., [151,160]), there is much reason to conclude that there is large-scale morphological variation in several clades of Mentha, making a clear general link of the full morphospace at the interspecies level unlikely to be found.

We stress that underestimations of the genetic and morphological diversity of mints can further bias sampling design and insufficient sampling efforts can indeed lead to spurious conclusions. Continued sampling of the same hybrids, varieties (cultivars) or special morphologies (as is the case with some herbarium specimens) may not shed new light on the overall evolutionary relationships within a genus, and may even generate flaws. According to Phillips et al. [161], in general, sample sizes of 15 to 25 (or 60) individuals per species are to be considered an absolute minimum level to obtain reliable estimates of genetic polymorphism at the species level, although it will depend on the species at hand [161-164]. However, the limited availability of funds, time and material frequently prevent such extensive sampling; hence, conclusions based on a handful of samples are the norm, although this serious caveat should be acknowledged, including from a statistical point of view.

Adding to the obvious complexity in genomic relationships and morphological overlaps between different mints, species assignment within this group of plants has been greatly complicated and confused by the historic description of a huge number of species, many of which are synonyms or based on a single individual with an unusual phenotype (e.g., [33]). The unrestrained proliferation of thousands of names (e.g., [38,39]) led to nomenclatural complicatedness, and as the tower of Babylon was built, perpetual and quasi-inherent confusion seemed to guarantee a persistent puzzling taxonomy. Chanting Babylonian plant labels without real-life metrics exerted on a standardized phenotypic space and without handling a sufficient sample size is counterproductive in phylogenetic research on cryptic taxa. Nomenclature is by nature hierarchical, but hyperdiversity breaks the limits of traditional species delimitations and makes classic nomenclature unfeasible. Hence, binomial nomenclature might not be able to offer an adequate solution on the species level as mints might indeed be genetically built multiway due to complex evolutionary relationships. Thus, Mentha is a classical example where the desire for a hierarchical and binomial nomenclature to fit a multidimensionally structured network of organisms complicates the understanding of the evolutionary history of a whole genus. 


\subsection{The Hybrid Status of Mentha spicata Revisited}

M. spicata is commonly accepted to have a hybrid origin and is thought to have arisen as an ancient stable allopolyploid between $M$. longifolia and $M$. suaveolens $[41,47,55,63,66,112,165,166]$. It is, however, different from the equivalently defined hybrid $M . \times$ rotundifolia, which is often mistaken for $M$. spicata. Thereby, it is hypothesized that $M$. spicata probably arose in cultivation [49], which might have been in Neolithic times, i.e., roughly about 10-11 $\mathrm{Ka}$ BCE. However, viewed from a historical perspective, all of this could be read as a persistent myth in which the many-headed dragon ' $M$. spicata' was gradually embeddeda myth that became shaped along misty pathways (e.g., $[41,45,47,106])$ and that is still very much alive today (e.g., $[63,66,112,166])$. Conclusions from repeated studies of morphology, chemistry and cytology, coupled with field experiments and genetic research, confirmed or enhanced the idea of such hybrid origin. In particular a genetically and morphologically intermediary position of ' $M$. spicata' (Figures 1 and 6) has often been (mis)interpreted as a clear sign of hybridization (e.g., [41,55]). The intermediate position between M. longifolia s.l. and M. suaveolens, also inspired by too many haloed plant labels clumsily fixed to sequence phylograms, has been implicitly framed as a unidirectional relationship with 'the two parents'. Findings from chloroplast data have further served as a suggestion that ' $M$. longifolia' is the maternal parent of M. spicata [93,107,167].

However, our results show that $M$. longifolia is also polyphyletic and that accessions labeled as M. spicata (s.l.) consist of a composite taxon, both genetically (Figure 1) and morphologically (Figure 7A). Our genotype-phenotype analysis suggests a separate clade that can be interpreted as M. spicata s.s., while other samples formerly labeled M. spicata (s.l.) reside under either $M$. longifolia s.s. or $M$. suaveolens s.l. We find no evidence that M. spicata s.s. has any M. suaveolens ITS alleles, which is peculiar if the species indeed is a true alloploid involving the latter as one of the parents. Hence, the argument that concerted evolution makes $M$. spicata ITS sequences closely related to M. suaveolens [66] is not supported here. With respect to this, we stress that the taxon known as 'Moroccan mint', which has traditionally been erroneously perceived as M. spicata, is genetically and phenotypically clearly distinct from M. spicata (Figure 6). It is found within M. suaveolens s.l., which might have added to the concerted evolution hypothesis on ' $M$. spicata'.

In conclusion, we do not find any evidence of a hybrid or cultivated origin of $M$. spicata. The subspecies ' 'labrata', as defined by Lebeau [52-54] and associated with cultivation, is just another polyphyletic construct that is situated in our phylogeny as part of a genetic mix of glabrous to extremely hairy forms within M. spicata s.s. (cluster 2.5; Figure 1). Besides, in practice, glabrous variants are also part of totally wild populations. Last but not least, Drew et al. [123] put basal phylogenetic splits within sect. Mentha as occurring in the period from the late Miocene to the Quaternary, several million years ago. Therefore, it seems quite improbable the M. spicata s.s. complex or any of the species within would be mainly the result of post-Ice Age human in(ter)vention.

We do, however, find about $15 \%$ phenotypic overlap among our samples from both the M. spicata and M. suaveolens-longifolia complexes, and hence, it is possible that some gene flow might have occurred between the two complexes (certainly in the case of cultivars), which may have confused taxonomic assignments in the past. However, this gene flow might have occurred in more occasional, less systematic and multidirectional ways. Given our results, we strongly recommend that the taxonomic status of $M$. spicata, including its lectotype, should be revised. A more suitable candidate for the lectotype might be specimen S-LINN-IDC 238.1 denoted by ' 2 viridis' in the Linnean herbarium (or alternatively LINN 730.5).

\section{Materials and Methods}

\subsection{Sampling}

We used mint accessions from 'Bright Mints', a permanent collection of living plants containing a large number $(>500)$ of mainly European specimens of Spicate mints. That collection was largely built up by field sampling directed by known historical locations 
identified on a variety of herbarium vouchers from Paris (P, France), Meise (BR, Belgium), Leiden (L, the Netherlands), Kew (K, United Kingdom), Genève (G, Switzerland), Namur (NAM, Belgium) and Copenhagen (C, Denmark). Additionally, samples from other collections or from garden centers were included. We selected accessions to maximize the phenotypic and genotypic variability. The main target species were $M$. spicata (including $M$. microphylla), the hybrid complex $M . \times$ rotundifolia $-M . \times$ villosa $-M . \times$ cordifolia and $M$. longifolia (all sensu lato) from Europe. We also included some accessions from geographically distant areas (in particular accessions from NCGR, Corvallis, US; Table S1).

Specimens were selected to represent the largest possible phenotypic variation using a number of criteria: (1) assuring large geographical spread among selected specimen and taxa, (2) including historically described taxa, (3) ensuring large phenotypic range, (4) mostly excluding repeatedly hybridized or sterile cultivars to avoid potential bias caused by human selection and (5) including 10 voucher specimens (see below) for which ribosomal sequences were available. The final selection included 90 accessions (Table S1). Additionally, two herbarium specimens (one equivalent to the lectotype of M. spicata, BM00064600) were also included in the genetic analysis but were not morphologically assessed. A further 69 ribosomal sequences from voucher specimens were retrieved and included in the phylogenetic analyses (Table S1). An additional sample of M. aquatica L. was sequenced but not morphologically evaluated. In total, this resulted in 162 different specimens or vouchers and finally in 212 different sequences genotypically evaluated, which is, as far as we know, the largest (Spicate) mint dataset compiled to date.

To minimize environmental and plasticity effects on the morphological assessment, all the acquired plants were grown under the same common garden conditions (SE of Antwerp, Belgium; $\left.51^{\circ} 03^{\prime} \mathrm{N}, 4^{\circ} 46^{\prime} \mathrm{E}\right)$. The plants were potted in $10 \mathrm{~L}$ pots containing potting soil ('DCM universal': dry matter $30 \%$, organic matter $20 \%, \mathrm{NPK} 1 \mathrm{~kg} / \mathrm{m}^{3}, \mathrm{pH}$ $5-6.5$ ), with the addition of loam soil (volume ca. 30\%) and approximately $200 \mathrm{~g}$ chalk grains ('DCM granular marine fossil coccolites', $45 \% \mathrm{CaO}, 2.5 \% \mathrm{MgO}$ ) to stabilize $\mathrm{pH}$. The plants were grown under a clear sky for at least one full season (10-16 months), ensuring they had sufficient amounts of water. At the start of May, extra nitrogen-potassium solution was provided (liquid N/K 6:3, diluted 1:200). To prevent damage or abnormal growth, the collection was treated with pesticides (fungicide: 'bio-cuprex garden' containing 50\% $\mathrm{H}_{3} \mathrm{ClCu}_{2} \mathrm{O}_{3}$; insecticide: 'Edialux Bio-Pyretrex Garden') and snails were systematically removed.

\subsection{DNA Extraction and Sequencing}

For 10 of the 90 samples in the living collection, ribosomal sequences were already available (Table S1). For the remaining 80 samples, fully extended leaves were selected and up to $100 \mathrm{mg}$ of material was fast frozen in liquid nitrogen and powdered with a mortar under a sterile PCR hood to avoid sample cross-contaminations. DNA was extracted using the NucleoSpin Plant II kit (Machery-Nagel) following the manufacturer's protocol. Preliminary experiments on a subset of samples showed difficulties with PCR amplification likely due to a large amount of PCR inhibitors, which is characteristic of aromatic plants. The DNA extracts were therefore diluted (20:1) prior to PCR amplification in order to limit the effects of such inhibitors.

Parts of the nuclear ribosomal region (ITS1-5.8S-ITS2) were PCR amplified using the forward primer $5^{\prime}$-AGAAGTCCACTGAACCTTATC- $3^{\prime}$ and the reverse primer $5^{\prime}$ CGCTTCTCCAGACTACAATTC-3' [168] in a $25 \mu \mathrm{L}$ reaction volume containing $1 X$ GoTaq reaction buffer (1.5 mM MgCl2), $0.2 \mathrm{mM}$ of each $\mathrm{dNTP}, 0.5 \mu \mathrm{M}$ of each primer, $0.5 \mathrm{U}$ of GoTaq DNA polymerase (Promega), $10 \mathrm{ng}$ of bovine serum albumin (BSA) and $2 \mu \mathrm{L}$ (ca. $10 \mathrm{ng}$ ) of diluted genomic DNA. The amplification conditions were as follows: (1) initial denaturation at $94{ }^{\circ} \mathrm{C}$ for $2 \mathrm{~min} 30 \mathrm{~s}$; (2) 40 cycles at $94{ }^{\circ} \mathrm{C}$ for $30 \mathrm{~s}, 54{ }^{\circ} \mathrm{C}$ for $30 \mathrm{~s}$ and $72{ }^{\circ} \mathrm{C}$ for $1 \mathrm{~min} 15 \mathrm{~s}$; and (3) final extension at $72{ }^{\circ} \mathrm{C}$ for $10 \mathrm{~min}$. The $\mathrm{PCR}$ products were visualized on a $2 \%$ agarose gel stained with Sybr Safe (ThermoFisher). The migration was performed for $50 \mathrm{~min}$ at $100 \mathrm{~V}$ and the picture was taken by a BioRad analyzer Gel Doc XR. PCR 
products were Sanger sequenced using the forward primer at Genewiz facilities (Leipzig, Germany). Samples with noisy chromatograms were resequenced using the reverse primer. The sequences were then assembled and phased using the software PHASE $[169,170]$ and Champuru $[147,171]$. The analysis of the patterns of double peaks in the forward and reverse sequences allows haplotypes to be inferred without cloning.

Preliminary analysis using ITS sequences showed that some samples belonging to different taxa within $M$. longifolia s.s. shared sequences that could not be distinguished (see Section 2). To further characterize the genetic diversity and relatedness of these samples, we amplified the 10 nuclear start codon targeted polymorphism (SCoT) markers described by Khan and Dhawan [172] (see also [58,173]) from a subset of samples (Table S1). The amplification products were visualized on a $3 \%$ agarose gel, and the presence and absence of polymorphic bands were manually scored and summarized in a binary matrix.

\subsection{Morphological Measurements}

For all living specimens, a total of 122 morphological used variables (from which 63 variables are categorical and 59 are continuous; Table S2) were extracted from a set of 116 directly measured or scored features. Categorical variables were either binary $(n=11$; mostly coded equivalents of multinomial variables) or ordinal ( $n=52$; concerning averages of twice independently scored values). In general, variables were measured on plants in full bloom (end of May/August and onwards depending on the species). However, for leaf shape measurements, leaves were sampled at least a few weeks before the plants started flowering and before mid-June. Twenty leaf-related variables were measured on a total of five to six scanned leaves (600 dpi scans fifth or sixth leaves from the top of plants) using Lamina 1.0.2 [174]. The mean of each continuous leaf variable was used for comparative analyses. Stems and flowers were simultaneously studied after selecting one well-developed, typical shoot/thyrse with cymes and flowers. One typical flower was chosen after microscopically (binocular $45 \times$ ) evaluating the flowers of the whole plant. The flower characteristics of calyx and corolla were measured from photographs (CMEX5 DC.5000C) of dissected materials in ImageFocus 4.0.

Only above-ground parts of mints that concern characteristics of the calyx $(n=38)$ or other generative features $(n=17)$ were studied. Further, many leaf variables $(n=45)$ and some stem features $(n=8)$ were included. Other variables concerned general plant characteristics $(n=4)$ or organoleptic properties, i.e., odor $(n=10)$. Although some other features were also observed (e.g., stamen length, anther color and stigma development), they were not systematically assessed here because of their strong variability within the same taxon, which was apparent by inspecting the plants. We primarily preferred features with more inter- than intrataxon variability.

\subsection{Data Analyses}

\subsubsection{Genetic Analyses}

Part of the ribosomal ITS region was sequenced for a total of 82 samples in this study (Table S1). In addition, 79 previously published ribosomal sequences from voucher specimens were retrieved from GenBank and included in the phylogenetic analyses (Table S1). All ITS sequences were aligned in MAFFT (E-INS-i parameters [175]), and a phylogenetic tree was reconstructed in BEAST v.1.10.4 [176] using $1 \times 10^{8}$ chains and a GTR + I + G nucleotide substitution model, determined as the best-fit model (AIC) using jModelTest2 [177] with the following priors: $\kappa: \operatorname{LogN}[1,1.25]$, initial $=2$; frequencies: dirichlet $[1,1]$; clock rate: fixed, value $=1$; tree model root height: tree prior in $[0, \infty]$, constant population size: $1 / x$, initial $=1$. The burn-in was set to $1,000,000$ and convergence was assessed in Tracer v1.7.1 [178]. The rooting of the tree was directed by the results, using a group of M. arvensis-M. canadensis samples as a posteriori outgroup (see Section 2). Phylogenetic clusters of sequences were identified using posterior probabilities $(\mathrm{PP})>0.6$.

We further constructed a haplotype network using HaplowebMaker [179] to delimit fields for recombination (FFRs), i.e., species clusters [180-182]. We used all 90 living 
specimens, 2 herbarium specimens and a limited number of voucher specimens (Table S1). Based on visual inspection of the haploweb, genetic subclusters were identified.

The presence-absence data of SCoT amplification bands were converted to a matrix of Jaccard's distances reflecting genetic dissimilarities across the samples. This and the distance matrix calculated from the ITS data were double factorized (principal components factoring, PCF; [183]), first separately and thereafter in combination (using original PCFscores of the first two analyses). The resulting PCF biplot, therefore, shows the information contained in both the ITS alignments and the SCoT data, resulting in a further genotype distinction on the subcluster level.

Finally, genetic distances (K2P-GD) were calculated between the specimen units for samples included in the discriminant analyses (DA, see below). A crosstable is presented containing per unit combination the minimal observed $G D$ value $\left(G D_{\min }\right)$. Automatic barcode gap discovery (ABGD) for primary species delimitation [70] and GMYC [146] were used to estimate the range of the possible number of species, and the results were compared to those of the mentioned crosstable analysis.

\subsubsection{Morphological Analyses}

Intercluster hybrid taxa, as identified by distinct sequences in different phylogenetic clusters, were excluded from the morphological analyses so as not to confound the analyses by human-induced selection or repetitively cross-bred strains. However, samples identified as $M . \times$ rotundifolia (L.) Huds. or hybrids with $M . \times$ billotiana (sensu Alfred Déségliseand Théophile Durand; hereafter as M. billotiana) were exceptions. Hybrids with M. suaveolens subsp. insularis (Req. ex Gren. \& Godr.) Greuter or M. suaveolens subsp. timija (Coss. ex Briq.) were also included as these were the only representatives of a specific genetic cluster.

To evaluate the morphological space of the identified genetic subclusters, we choose a linear methodology and performed discriminant analysis (DA, R package 'mass' [184]) after having explored variable suitability by executing preparatory analyses such as penalized discriminant analysis on the full (122 variables) dataset as described below. Ward's cluster method ( $n=7$, Euclidian distances; Table S2) was applied on a standardized variable subset after variable selection (variables with a correlation coefficient $>0.80$ were removed to avoid multicollinearity effects; Table S2). The resulting Ward's groups were projected in the DA space. Different relationships were assessed: the association (lambda) between Ward's groups and specimen units (see below), the relationship (Kruskal-Wallis) between Ward's groups and DA axes and the (visual) relationship between the Ward's groups and existing plant labels.

For DA, we grouped plant samples genotypically as 'specimen units' based on recognized phylogenetic subclusters ( $\mathrm{PP}>0.6$ ) and subclusters identified using the haploweb method and the SCoT analyses. DA maximizes the separation between predefined groups of samples (specimen units). Hence, morphotypes can be distinguished in a genotypeconstrained space where genotypic specimen units are arranged according to their mutual morphological resemblances. Only lasso-selected independent variables entered the best model, and the magnitude and significance of Wilk's lambda were tested (dispersion prerequisite: $\Delta_{\mathrm{W}}<0.05$ ). Analyses were done in R 4.0.3. We evaluated the suitability of candidate variable subsets by different DA-performance-oriented criteria (proportion of between-unit dispersion (\%) provided the lowest possible number of modeled variables $\left(\mathrm{n}_{\min }\right)$; representativity of DA-contained information for the whole dataset (Stewart-Love canonical redundancy index); and generic systematic (ranked) cohesion over the genotypic units (GLM-R $\left.{ }^{2}\right)$ ) after selecting these candidate variable subsets out of the 122 variables by means of different lasso-penalized techniques (using packages 'penalizedLDA' [185] and 'glmnet' [186]) that outperformed 'subselect' [187] (results not presented here). The Stewart-Love canonical redundancy index, an index to measure the degree to which one set of variables can predict another set of variables, was calculated by relating the first six DA-dimensions based on the penalized variable subset with PCF (first six factors) including all 122 morphological variables (hence also binary variables [188,189]). 
The idea behind this variable selection approach is to finally arrive, within a comparative DA-framework, at a limited subset of DA-modeled variables that perform well in the mentioned criteria without getting necessarily stacked up into one particular technique. Thereby, the lasso technique is especially aimed at reducing large variable sets (compared to sparse sample numbers) by penalization. When the lasso penalty tuning parameter $(\lambda)$ is high, it leads to increased lasso penalties on, e.g., discriminant vectors, which generates sparse feature subsets in such penalized models. In DA, features with a strong within-class variability undergo greater penalization (creating a sparse classifier for which the decision rule involves only a subset of the features [190]). The minimum number of selected variables over all the penalized models puts the limit $\left(\mathrm{n}_{\min }\right)$ for included number of variables in the final DA.

Visualization was limited to the first three dimensions (gplot2 [191]). A 3D cube representation [192] is given to ease interpretation, more specifically in relation to the genetic main clusters.

Finally, a cluster analysis (centroid linkage) was done on the DA scores of the first three dimensions to pinpoint the different morphoclouds and, more specifically, those accessions that are morphologically overlapping while belonging to different genetic main clusters. The morphocloud analysis results were then plotted on the ITS phylogenetic tree to demonstrate correspondence and difference between the modeled morphology and ITS-SCoT genotype phylogeny.

Supplementary Materials: The following material is available online at https:/ /www.mdpi.com/ article/10.3390/plants10040819/s1, Figure S1: Ward's groups along the first three DA axes, Figure S2: Dendrogram of centroid linkage cluster analysis on DA scores, Figure S3: A generalized comparison of nrDNA phylogenetic results from different studies with an extract of the here presented phylogeny based on ITS. Figure S4: A generalized comparison of cpDNA phylogenetic results from different studies with an extract of the here presented phylogeny based on ITS. Table S1: Overview of accessions with their use and general information (GenBank, herbarium, etc.). Table S2: Overview of variables used for phenotype description.

Author Contributions: Conceptualization, O.C.G.H. and J.K.O.; methodology, O.C.G.H., N.D., J.M. and J.K.O.; investigation, O.C.G.H. (sampling and garden setup, collecting morphological and genetic data) and N.D. (molecular analyses); formal analysis, O.C.G.H.; visualization, J.K.O.; writing—original draft, O.C.G.H. and J.K.O.; writing—review and editing, N.D. and J.M.; supervision, O.C.G.H.; project administration, O.C.G.H.; resources, O.C.G.H.; data curation, O.C.G.H.; Funding acquisition, O.C.G.H. All authors have read and agreed to the published version of the manuscript.

Funding: The research (more specifically, all molecular analyses and garden setup) was funded by Oteas consultancy company.

Institutional Review Board Statement: Not applicable.

Informed Consent Statement: Not applicable.

Data Availability Statement: Sequences resulting from this study are deposited in GenBank. All other data not contained in the supplementary files are available upon request from the corresponding author.

Acknowledgments: We are very grateful to Ann Walraevens (Bright Mints, Belgium) for providing access to her collection and for assisting in sample selection, preparation and processing. The National Clonal Germplasm Repository (Corvallis, US) was so kind as to provide extra mint resources, and we are also grateful to Dirk Descamps, Walter Terryn, Attila Szkukálek, Jean Levy and Peter Oldfield for open access to their collections. Louis Schoeters, Hugo Ruysseveldt, Herman Vannerom, Hans Øllgaard, Yorick Ferrez and Lukas Petrulaitis provided us with interesting material or valuable herbarium specimens of cryptic taxa. We also thank Philippe Martin for assisting with specimen inspection in the herbarium of the University of Namur, and for the possibility to use sample material for molecular analyses. Finally, we want to thank Olof Ryding (Botanisk Museum, Copenhagen) for fruitful conversations and Igor Bartish (Academic Editor Plants) for his much appreciated comments. 
Conflicts of Interest: Olivier Heylen received funding from Oteas consultancy company (founded by Olivier Heylen), for financing the analysis of all molecular data and garden setup materials. Nicolas Debortoli and Jonathan Marescaux (e-biom, co-founder and chairman) have been involved as a consultant and expert witness in the company e-biom, responsible for all molecular analyses in this study.

\section{References}

1. Cutter, A.D.; Jovelin, R.; Dey, A. Molecular Hyperdiversity and Evolution in Very Large Populations. Mol. Ecol. 2013, 22, 2074-2095. [CrossRef] [PubMed]

2. Willmore, K.E.; Young, N.M.; Richtsmeier, J.T. Phenotypic Variability: Its Components, Measurement and Underlying Developmental Processes. Evol. Biol. 2007, 34, 99-120. [CrossRef]

3. Alix, K.; Gérard, P.R.; Schwarzacher, T.; Heslop-Harrison, J.S. (Pat) Polyploidy and Interspecific Hybridization: Partners for Adaptation, Speciation and Evolution in Plants. Ann. Bot. 2017, 120, 183-194. [CrossRef]

4. Lucchesi, J.C. Epigenetics, Nuclear Organization E Gene Function; Oxford University Press: Oxford, UK, 2019.

5. Vereecken, N.J.; Cozzolino, S.; Schiestl, F.P. Hybrid Floral Scent Novelty Drives Pollinator Shift in Sexually Deceptive Orchids. BMC Evol. Biol. 2010, 10. [CrossRef] [PubMed]

6. Rieseberg, L.H.; Wood, T.E.; Baack, E.J. The Nature of Plant Species. Nature 2006, 440, 524-527. [CrossRef] [PubMed]

7. Adams, M.; Raadik, T.A.; Burridge, C.P.; Georges, A. Global Biodiversity Assessment and Hyper-Cryptic Species Complexes: More Than One Species of Elephant in the Room? Syst. Biol. 2014, 63, 518-533. [CrossRef] [PubMed]

8. Bickford, D.; Lohman, D.J.; Sodhi, N.S.; Ng, P.K.L.; Meier, R.; Winker, K.; Ingram, K.K.; Das, I. Cryptic Species as a Window on Diversity and Conservation. Trends Ecol. Evol. 2007, 22, 148-155. [CrossRef]

9. Jörger, K.M.; Schrödl, M. How to Describe a Cryptic Species? Practical Challenges of Molecular Taxonomy. Front. Zool. 2013, 10, 59. [CrossRef]

10. Coates, D.J.; Byrne, M.; Moritz, C. Genetic Diversity and Conservation Units: Dealing with the Species-Population Continuum in the Age of Genomics. Front. Ecol. Evol. 2018, 6, 165. [CrossRef]

11. Struck, T.H.; Feder, J.L.; Bendiksby, M.; Birkeland, S.; Cerca, J.; Gusarov, V.I.; Kistenich, S.; Larsson, K.H.; Liow, L.H.; Nowak, M.D.; et al. Finding Evolutionary Processes Hidden in Cryptic Species. Trends Ecol. Evol. 2018, 33, 153-163. [CrossRef]

12. Cerca, J. On the Origin of Cryptic Species: Insights from the Stygocapitella Species Complex. Ph.D. Thesis, University of Oslo, Natural History Museum Faculty of Mathematics and Natural Sciences, Oslo, Norway, 2019.

13. Pentinsaari, M.; Vos, R.; Mutanen, M. Algorithmic Single-Locus Species Delimitation: Effects of Sampling Effort, Variation and Nonmonophyly in Four Methods and 1870 Species of Beetles. Mol. Ecol. Resour. 2017, 17, 393-404. [CrossRef]

14. Luo, A.; Ling, C.; Ho, S.Y.W.; Zhu, C.-D. Comparison of Methods for Molecular Species Delimitation Across a Range of Speciation Scenarios. Syst. Biol. 2018, 67, 830-846. [CrossRef]

15. Martoni, F.; Bulman, S.; Pitman, A.; Taylor, G.; Armstrong, K. DNA Barcoding Highlights Cryptic Diversity in the New Zealand Psylloidea (Hemiptera: Sternorrhyncha). Diversity 2018, 10, 50. [CrossRef]

16. Rüegg, S.; Bräuchler, C.; Geist, J.; Heubl, G.; Melzer, A.; Raeder, U. Phenotypic Variation Disguises Genetic Differences among Najas Major and N. Marina, and Their Hybrids. Aquat. Bot. 2019, 153, 15-23. [CrossRef]

17. Semenova, M.V.; Enina, O.L.; Shelepova, O.V. Intra- and Interspecific Variability of Mentha Arvensis L- and M. Canadensis L. Vavilovskii Zhurnal Genet. Sel. 2019, 23, 1067-1075. [CrossRef]

18. Lexer, C.; Joseph, J.; van Loo, M.; Prenner, G.; Heinze, B.; Chase, M.W.; Kirkup, D. The Use of Digital Image-Based Morphometrics to Study the Phenotypic Mosaic in Taxa with Porous Genomes. TAXON 2009, 58, 5-20. [CrossRef]

19. Pinho, C.; Hey, J. Divergence with Gene Flow: Models and Data. Annu. Rev. Ecol. Evol. Syst. 2010, 41, 215-230. [CrossRef]

20. Bräuchler, C.; Meimberg, H.; Heubl, G. Molecular Phylogeny of Menthinae (Lamiaceae, Nepetoideae, Mentheae)—Taxonomy, Biogeography and Conflicts. Mol. Phylogenet. Evol. 2010, 55, 501-523. [CrossRef]

21. Zhao, F.; Chen, Y.-P.; Salmaki, Y.; Drew, B.T.; Wilson, T.C.; Scheen, A.-C.; Celep, F.; Bräuchler, C.; Bendiksby, M.; Wang, Q.; et al. An Updated Tribal Classification of Lamiaceae Based on Plastome Phylogenomics. BMC Biol. 2021, 19. [CrossRef]

22. Briquet, J. Lieferung. Labiatae. IV. Teil, 3. Abteilung a, Bogen 18 bis 20. In Die natürlichen Pflanzenfamilien nebst ihren Gattungen und wichtigeren Arten insbesondere den Nutzpflanzen; Engler, A., Prantl, K., Eds.; Verlag von Wilhelm Engelmann: Leipzig, Germany, 1896.

23. Tucker, A.O. Genetics and Breeding of the Genus Mentha: A Model for Other Polyploid Species with Secondary Constituents. J. Med. Act. Plants 2012, 1, 19-29. [CrossRef]

24. Bräuchler, C. Delimitation and Revision of the Genus Thymbra (Lamiaceae). Phytotaxa 2018, 369, 15-27. [CrossRef]

25. Chen, X.H.; Zhang, F.Y.; Yao, L. Chloroplast DNA Molecular Characterization and Leaf Volatiles Analysis of Mint (Mentha; Lamiaceae) Populations in China. Ind. Crops Prod. 2012, 37, 270-274. [CrossRef]

26. Jabeen, A.; Guo, B.; Abbasi, B.H.; Shinwari, Z.K.; Mahmood, T. Phylogenetics of Selected Mentha Species on the Basis of Rps8, Rps11 and Rps14 Chloroplast Genes. J. Med. Plants Res. 2012, 6, 30-36. [CrossRef]

27. Schanzer, I.A.; Semenova, M.V.; Shelepova, O.V.; Voronkova, T.V. Genetic Diversity and Natural Hybridization in Populations of Clonal Plants of Mentha Aquatica L. (Lamiaceae). Wulfenia 2012, 19, 131-139.

28. Ahmed, S.M. Molecular Identification of Lavendula Dentata L., Mentha Longifolia (L.) Huds. and Mentha $\times$ Piperita L. by DNA Barcodes. Bangladesh J. Plant Taxon. 2018, 25, 149-157. [CrossRef] 
29. Ahmed, S.M.; Alamer, K.H. Discriminating Lamiaceae Species from Saudi Arabia Using Allozyme and Specific DNA Markers. Pak. J. Bot. 2018, 50, 969-975.

30. Jedrzejczyk, I.; Rewers, M. Genome Size and ISSR Markers for Mentha L. (Lamiaceae) Genetic Diversity Assessment and Species Identification. Ind. Crops Prod. 2018, 120, 171-179. [CrossRef]

31. Abasi, F.; Ahmad, I.; Khan, S.U.; Ahmad, K.S.; Ulfat, A.; Khurshid, R. Estimation of Genetic Diversity in Genus Mentha Collected From Azad Jammu And Kashmir, Pakistan. bioRxiv 2019. [CrossRef]

32. Soilhi, Z.; Trindade, H.; Vicente, S.; Gouiaa, S.; Khoudi, H.; Mekki, M. Assessment of the Genetic Diversity and Relationships of a Collection of Mentha Spp. in Tunisia Using Morphological Traits and ISSR Markers. J. Hortic. Sci. Biotechnol. 2020, 95, 483-495. [CrossRef]

33. Tucker, A.O.; Naczi, R.F.C. Mentha: An Overview of Its Classification and Relationships. In Mint. The Genus Mentha; Lawrence, B.M., Ed.; CRC Press: Boca Raton, FL, USA, 2006; pp. 1-40.

34. Borissova, A.G. Genus 1301. Mentha L. In Flora of the U.S.S.R.; Shishkin, B.K., Landau, N., Eds.; Keterpress Enterprises: Jerusalem, Israel, 1977; pp. 427-450. ISBN 0-7065-1573-0.

35. Jamzad, Z. Eremostachys Lanata and Mentha Mozaffarianii, Two New Labiatae from Iran. Iran. J. Bot. 1987, 3, 111-116.

36. Jančić, R. Mentha Serbica R.Jančić, Sp. Nov- a New Species of the Genus Mentha L. (Lamiaceae). Glas. Prir. Muzeja U Beogr. Ser. B 1989, 43/44, 27-33.

37. Conn, B.J.; Duval, D.J. Mentha Atrolilacina (Lamiaceae), a New Species from South Australia. Telopea 2010, 12, 521-524. [CrossRef]

38. Gandoger, M. Menthae Novae, Imprimis Europaeae. Bull. Soc. Imp. Nat. Moscou 1883, 58, 14-102.

39. Topitz, A. Ungarische Minzen. Ung. Bot. Bl. 1916, 15, 125-168.

40. Duda, T.F.; Bolin, M.B.; Meyer, C.P.; Kohn, A.J. Hidden Diversity in a Hyperdiverse Gastropod Genus: Discovery of Previously Unidentified Members of a Conus Species Complex. Mol. Phylogenet. Evol. 2008, 49, 867-876. [CrossRef]

41. Harley, R.M.; Brighton, C.A. Chromosome Numbers in the Genus Mentha L. Bot. J. Linn. Soc. 1977, 74, 71-96. [CrossRef]

42. Schürhoff, P.N. Zytologische Und Genetische Untersuchungen an Mentha Und Ihre Bedeutung Für Die Pharmakognosie. Arch. Pharm. 1929, 267, 515-526. [CrossRef]

43. Lietz, J. Beiträge Zur Zytologie Der Gattung Mentha; Friedrich-Wilhelms-Universität: Berlin, Germany, 1930.

44. Ruttle, M.L. Cytological Embryological Studies Genus Mentha. Gartenbauwissenschaft 1931, 4, 428-468.

45. Morton, J.K. The Chromosome Numbers of the British Menthae. Watsonia 1956, 3, $244-252$.

46. Harley, R.M. Taxonomic Studies in the Genus Mentha. Ph.D. Thesis, Oxford University, Oxford, UK, 1963.

47. Harley, R.M. The Spicate Mints. Proc. Bot. Soc. Br. Isles 1967, 6, 369-372.

48. Harley, R.M. Notes on the Genus Mentha (Labiatae). Bot. J. Linn. Soc. 1972, 65, 250-253.

49. Harley, R.M. Mentha. In Flora Europaea, 3; Tutin, T.G., Heywood, V.H., Burges, N.A., Moore, D.M., Valentine, D.H., Walters, S.M., Webb, D.A., Eds.; Cambridge Universty Press: Cambridge, UK, 1972; pp. 183-186.

50. Harley, R.M. Mentha. In Hybridization and the Flora of the British Isles; Stace, C.A., Ed.; Academic Press: London, UK, 1975; pp. 383-390.

51. Harley, R.M. Mentha L. In Hybrid Flora of the British Isles; Stace, C.A., Preston, C.D., Pearman, D.A., Eds.; Botanical Society of Britain \& Ireland: London, UK, 2016; pp. 255-262.

52. Lebeau, J. Mentha L. (Menthe. Munt. Minze). In Nouvelle flore de la Belgique, du Grand-Duché de Luxembourg, du nord de la France et des Régions Voisines (Ptéridophytes et Spermatophytes); De Langhe, J.-E., Delvosalle, L., Duvigneaud, J., Lambinon, J., Vanden Berghen, C., Eds.; Édition du Patrimoine du Jardin Botanique National de Belgique: Meise, Belgium, 1973; pp. $411-414$.

53. Lebeau, J. Appellations Nouvelles de Mentha (Labiatae) Hybrides, et Proposition Du Rang Nouveau de Subhybride. Bull. Jard. Bot. Natl. Belg. Bull. Van Natl. Plantentuin Van Belg. 1974, 44, 249-257. [CrossRef]

54. Lebeau, J. Nouvelles Mises Au Point Dans Le Genre Mentha. Nat. Mosana 1974, 27, 109-141.

55. Gobert, V.; Moja, S.; Colson, M.; Taberlet, P. Hybridization in the Section Mentha (Lamiaceae) Inferred from AFLP Markers. Am. J. Bot. 2002, 89, 2017-2023. [CrossRef]

56. Wang, H.T.; Yu, X.; Liu, Y.; Liang, C.Y.; Li, W.L. Analysis of Genetic Variability and Relationships among Mentha L. Using the Limonene Synthase Gene, LS. Gene 2013, 524, 246-252. [CrossRef]

57. Simon, C. An Evolving View of Phylogenetic Support. Syst. Biol. 2020, syaa068. [CrossRef]

58. Khan, N.; Singh, S.; Dhawan, S.S. Development of Species Specific SCoT Markers and Analysis of Genetic Diversity among Mentha Genotypes. Int. J. Innov. Sci. Eng. Technol. 2017, 4, 145-156.

59. Celenk, S.; Tarimcilar, G.; Bicakci, A.; Kaynak, G.; Malyer, H. A Palynological Study of the Genus Mentha L. (Lamiaceae). Bot. J. Linn. Soc. 2008, 157, 141-154. [CrossRef]

60. Panjeshahin, Z.; Sharifi-Sirchi, G.-R.; Samsampour, D. Genetic and Morphological Diversity of Wild Mint "Mentha Longifolia (L.) Hudson Subsp. Noeana (Briq.) Briq." in South and Southeastern Iran. J. Med. Plants Prod. 2018, 1, 105-115. [CrossRef]

61. Ahmad, I.; Khan, S.U.; Khan, A.; Amjad, M.S.; Abbasi, F. Reassessment of Mentha Species from Kunhar River Catchment Using Morphological and Molecular Markers. ANADOLU 2018, 28, 2018.

62. El-Kashoury, E.S.A.; El-Askary, H.I.; Kandil, Z.A.; Salem, M.A. Botanical and Genetic Characterization of Mentha Suaveolens Ehrh. Cultivated in Egypt. Pharmacogn. J. 2013, 5, 228-237. [CrossRef]

63. Bokić, B.S. Morfološka i Fitohemijska Karakterizacija Predstavnika Sekcija Pulegium (Mill.) Lam. \& DC. 1805 i Mentha (Mentha L., Lamiaceae) Sa Balkanskog Poluostrva i Južnog Dela Panonske Nizije. Ph.D. Thesis, Universitei U Novom Sadu, Prirodnomatematički Fakultet Departman za Biologiju I Ekologiju, Novi Sad, Serbia, 2021. 
64. Youssef, A.I.; Deeb, G.H.; Bitar, G. A Study of Genetic Variations of Genetic Types of Mentha Aquatica Distributed in Coastal Region Using PCR-RAPD Technique. Tishreen Univ. J. Res. Sci. Stud. Biol. Sci. Ser. 2011, 33, 183-198.

65. Rodrigues, L.; Póvoa, O.; van den Berg, C.; Figueiredo, A.C.; Moldão, M.; Monteiro, A. Genetic Diversity in Mentha Cervina Based on Morphological Traits, Essential Oils Profile and ISSRs Markers. Biochem. Syst. Ecol. 2013, 51, 50-59. [CrossRef]

66. Gobert, V.; Moja, S.; Taberlet, P.; Wink, M. Heterogeneity of Three Molecular Data Partition Phylogenies of Mints Related to M. x Piperita (Mentha; Lamiaceae). Plant Biol. 2006, 8, 470-485. [CrossRef] [PubMed]

67. Kalfagianni, A. DNA Barcoding of Native Plants; Use of «DNA Barcodes» ITS, MatK and TrnH-PsbA to Identify Native Plants of Genus Mentha in Chios (Greece) and Erythrae Peninsula (Turkey). Postgraduate studies Program Conservation of Biodiversity and Sustainable Exploitation of Native Plants (BNP). Ph.D. Thesis, Aristotle University of Thessaloniki School of Biology, Thessaloniki, Greece, 2012.

68. Tucker, A.O.; Harley, R.M.; Fairbrothers, D.E. The Linnaean Types of Mentha (Lamiaceae). TAXON 1980, 29, 233-255. [CrossRef]

69. Qin, Y.; Li, M.; Cao, Y.; Gao, Y.; Zhang, W. Molecular Thresholds of ITS2 and Their Implications for Molecular Evolution and Species Identification in Seed Plants. Sci. Rep. 2017, 7, 17316. [CrossRef]

70. Puillandre, N.; Lambert, A.; Brouillet, S.; Achaz, G. ABGD, Automatic Barcode Gap Discovery for Primary Species Delimitation. Mol. Ecol. 2012, 21, 1864-1877. [CrossRef]

71. Hedge, I.C. A Global Survey of the Biogeography of the Labiatae. In Advances in Labiatae Science; Harley, R.M., Reynolds, T., Eds.; Royal Botanic Gardens, Kew: Kew, UK, 1992; pp. 7-17.

72. Schemske, D.W.; Bradshaw, H.D. Pollinator Preference and the Evolution of Floral Traits in Monkeyflowers (Mimulus). Proc. Natl. Acad. Sci. USA 1999, 96, 11910-11915. [CrossRef]

73. Cozzolino, S.; Scopece, G. Specificity in Pollination and Consequences for Postmating Reproductive Isolation in Deceptive Mediterranean Orchids. Philos. Trans. R. Soc. Lond. B. Biol. Sci. 2008, 363, 3037-3046. [CrossRef]

74. Lowry, D.B.; Modliszewski, J.L.; Wright, K.M.; Wu, C.A.; Willis, J.H. The Strength and Genetic Basis of Reproductive Isolating Barriers in Flowering Plants. Philos. Trans. R. Soc. Lond. B. Biol. Sci. 2008, 363, 3009-3021. [CrossRef]

75. Farré-Armengol, G.; Filella, I.; Llusia, J.; Peñuelas, J. Relationships among Floral VOC Emissions, Floral Rewards and Visits of Pollinators in Five Plant Species of a Mediterranean Shrubland. Plant Ecol. Evol. 2015, 148, 90-99. [CrossRef]

76. Rezende, L.; Suzigan, J.; Amorim, F.W.; Moraes, A.P. Can Plant Hybridization and Polyploidy Lead to Pollinator Shift? Acta Bot. Bras. 2020, 34, 229-242. [CrossRef]

77. Warren, J. Is Wind-Mediated Passive Leaf Movement an Effective Form of Herbivore Defence? Plant Ecol. Evol. 2015, 148, 52-56. [CrossRef]

78. Schwarzbach, A.E.; Donovan, L.A.; Rieseberg, L.H. Transgressive Character Expression in a Hybrid Sunflower Species. Am. J. Bot. 2001, 88, 270-277. [CrossRef]

79. Rosenthal, D.M.; Schwarzbach, A.E.; Donovan, L.A.; Raymond, O.; Rieseberg, L.H. Phenotypic Differentiation between Three Ancient Hybrid Taxa and Their Parental Species. Int. J. Plant Sci. 2002, 163, 387-398. [CrossRef]

80. Lawrence, B.M. A Study of the Monoterpene Interrelationships in the Genus Mentha with Special Reference to the Origin of Pulegone and Menthofuran. Ph.D. Thesis, Faculty of Science and Engineering, University of Groningen, Groningen, The Netherlands, 1978.

81. Kokkini, S. Chemical Races Within the Genus Mentha L. In Essential Oils and Waxes. Modern Methods of Plant Analysis; Linskens, H.F., Jackson, J.F., Eds.; Springer: Berlin/Heidelberg, Germany, 1991; Volume 12, pp. 63-78.

82. Voirin, B.; Bayet, C.; Faure, O.; Jullien, F. Free Flavonoid Aglycones as Markers of Parentage in Mentha Aquatica, M. Citrata, M. Spicata and M. x Piperita. Phytochemistry 1999, 50, 1189-1193. [CrossRef]

83. Shasany, A.K.; Shukla, A.K.; Gupta, S.; Rajkumar, S.; Khanuja, S.P.S. AFLP Analysis for Genetic Relationships among Mentha Species. Plant Genet. Resour. Newsl. IPGRIFAO 2005, 144, 14-19.

84. Chengyuan, L.; Wei-lin, L.; Yong, Z.; BoHeng, X.; Xiao-yue, W. Study on Morphological Diversity of Mentha Haplocalyx Briq. Med. Plant 2011, 2, 1-3.

85. Barzin, G.; Mazooji, A.; Salimpour, F. Chemotaxonomy of Four Varieties of Mentha Longifolia L. Using Essential Oil Composition Markers. J. Biodivers. Environ. Sci. JBES 2014, 5, 172-176.

86. Hoque, A.; Rumman, R.; Akter, K.T.; Choudhury, T.I.; Faisal, W. Morphological Characterization and Evaluation of Twenty Two Mint Germplasm. Res. Rev. J. Crop Sci. Technol. 2014, 4, 4-12. [CrossRef]

87. Hanafy, D.M.; Prenzler, P.D.; Hill, R.A.; Burrows, G.E. Leaf Micromorphology of 19 Mentha Taxa. Aust. J. Bot. 2019, 67, 463. [CrossRef]

88. Venkatesha, K.T.; Singh, V.R.; Padalia, R.; Verma, R.; Upadyay, R.; Kumar, R.; Chauhan, A. Genetic Variability, D2 Analysis and Characters Association among Quantitative and Qualitative Traits of Spearmint (Mentha Spicata L.). Trends Phytochem. Res. 2019, 3, 101-108.

89. Bokić, B.S.; Rat, M.M.; Kladar, N.V.; Anačkov, G.T.; Božin, B.N. Chemical Diversity of Volatile Compounds of Mints from Southern Part of Pannonian Plain and Balkan Peninsula-New Data. Chem. Biodivers. 2020, 17. [CrossRef] [PubMed]

90. Mamadalieva, N.Z.; Hussain, H.; Xiao, J. Recent Advances in Genus Mentha: Phytochemistry, Antimicrobial Effects, and Food Applications. Food Front. 2020, 1-24. [CrossRef]

91. Mack, C. Morphologische, Mikroskopische Und Analytisch-Biochemische Untersuchungen Zur Differenzierung Verschiedener Arten Und Sorten Der Gattung Mentha/Claudia Mack; Institut für Pflanzenwissenschaften, Karl-Franzens-Universität: Graz, Austria, 2010. 
92. Srivastava, A.; Shasany, A.K.; Kumar, S.; Khanuja, S.P.S.; Bahl, J.R.; Sharma, S. Plant Genetic Resources Newsletter-Genetic Diversity Assessment of Mentha Spicata L. Germplasm through RAPD Analysis. Plant Genet. Resour. Newsl. 2002, 130, 1-5.

93. Bunsawatt, J.; Elliott, N.E.; Hertweck, K.L.; Sproles, E.; Alice, L.A. Phylogenetics of Mentha (Lamiaceae): Evidence from Chloroplast DNA Sequences. Syst. Bot. 2004, 29, 959-964. [CrossRef]

94. Vining, K.J.; Zhang, Q.; Tucker, A.O.; Smith, C.; Davis, T.M. Mentha Longifolia (L.) L.: A Model Species for Mint Genetic Research. HortScience 2005, 40, 1225-1229. [CrossRef]

95. Momeni, S.; Shiran, B.; Razmjoo, K. Genetic Variation in Iranian Mints on the Bases of RAPD Analysis. Pak. J. Biol. Sci. 2006, 9 , 1898-1904. [CrossRef]

96. Al-Rawashdeh, I.M. Molecular Taxonomy Among Mentha Spicata, Mentha Longifolia and Ziziphora Tenuior Populations Using the RAPD Technique. Jordan J. Biol. Sci. 2011, 4, 63-70.

97. Theodoridis, S.; Stefanaki, A.; Tezcan, M.; Aki, C.; Kokkini, S.; Vlachonasios, K.E. DNA Barcoding in Native Plants of the Labiatae (Lamiaceae) Family from Chios Island (Greece) and the Adjacent Çeşme-Karaburun Peninsula (Turkey). Mol. Ecol. Resour. 2012, 12, 620-633. [CrossRef]

98. Kumar, B.; Kumar, U.; Yadav, H.K. Identification of EST-SSRs and Molecular Diversity Analysis in Mentha Piperita. Crop J. 2015, 3, 335-342. [CrossRef]

99. Capuzzo, A.; Maffei, M.E. Molecular Fingerprinting of Peppermint (Mentha Piperita) and Some Mentha Hybrids by Sequencing and RFLP Analysis of the 5S RRNA Non-Transcribed Spacer (NTS) Region. Plant Biosyst. 2016, 150, 236-243. [CrossRef]

100. Sabboura, D.; Yacoub, R.; Lawand, S. Assessment of Genetic Relationships among Mint Species. Int. J. ChemTech Res. 2016, 9, 462-468.

101. Biswas, K.; Rohira, H.; Biswas, R. Molecular Studies of In-Vitro Propagated Three Mentha Species on “KFA+"Media. Int. J. Appl. 2017, 12, 211-217.

102. Vining, K.J.; Johnson, S.R.; Ahkami, A.; Lange, I.; Parrish, A.N.; Trapp, S.C.; Croteau, R.B.; Straub, S.C.K.; Pandelova, I.; Lange, B.M. Draft Genome Sequence of Mentha Longifolia and Development of Resources for Mint Cultivar Improvement. Mol. Plant 2017, 10, 323-339. [CrossRef]

103. Wang, K.; Li, L.; Hua, Y.; Zhao, M.; Li, S.; Sun, H.; Lv, Y.; Wang, Y. The Complete Chloroplast Genome of Mentha Spicata, an Endangered Species Native to South Europe. Mitochondrial DNA Part B Resour. 2017, 2, 907-909. [CrossRef]

104. Vining, K.J.; Pandelova, I.; Hummer, K.E.; Bassil, N.V.; Contreras, R.; Neill, K.; Chen, H.; Parrish, A.N.; Lange, B.M. Genetic Diversity Survey of Mentha Aquatica L. and Mentha Suaveolens Ehrh., Mint Crop Ancestors. Genet. Resour. Crop Evol. 2019, 66, 825-845. [CrossRef]

105. Moshrefi-Araghi, A.; Nemati, H.; Azizi, M.; Moshtaghi, N.; Shoor, M. Study of Genetic Diversity of Some Genotypes of Iranian Wild Mint (Mentha Longifolia L.) Using ISSR Marker and Its Correlation with Dry Yield and Essential Oil Content. Agric. Biotechnol. J. 2020, 12, 117-140. [CrossRef]

106. Briquet, J. Fragmenta Monographiae Labiaterum-Fascicule Ier. Révision Systématique Des Groupes Spécifiques et Subspécifiques Dans Le Sous-Genre Menthastrum Du Genre Mentha. Bull. Trav. Société Bot. Genève 1889, 5, $20-122$.

107. Bunsawatt, J. Mentha (Lamiaceae) Phylogenetic Analysis Using Chloroplast TRNL-TRNF and Nuclear Ribosomal DNA ITS Sequences. Master's Thesis, Western Kentucky University, Bowling Green, KY, USA, 2002.

108. Capuzzo, A.; Maffei, M.E. Molecular Fingerprinting of Some Mentha Species by Sequencing and RFLP Analysis of the 5S-RRNA Non-Transcribed Spacer Region. Plant Biosyst. 2014, 148, 683-690. [CrossRef]

109. Tucker, A.; Chambers, H. Mentha Canadensis L. (Lamiaceae): A Relict Amphidiploid from the Lower Tertiary. Taxon 2002, 51, 703. [CrossRef]

110. Thakur, V.V.; Tiwari, S.; Tripathi, N.; Sapre, S. DNA Barcoding and Phylogenetic Analyses of Mentha Species Using RbcL Sequences. Ann. Phytomed. 2016, 5, 59-62.

111. Choupani, A.; Shojaeiyan, A.; Maleki, M. Genetic Relationships of Iranian Endemic Mint Species, Mentha Mozaffariani Jamzad and Some Other Mint Species Revealed by ISSR Markers. Biotechnologia 2019, 100, 19-28. [CrossRef]

112. Yaghini, H.; Sabzalian, M.R.; Rahimmalek, M.; Garavand, T.; Maleki, A.; Mirlohi, A. Seed Set in Inter Specific Crosses of Male Sterile Mentha Spicata with Mentha Longifolia. Euphytica 2020, 216. [CrossRef]

113. Rahimmalek, M. Study of Genetic Relationships of Some Mint Species Using R-ISSR Markers. Argicult. Biotechnol. 2011, 10, 11-17.

114. Zinodini, A.; Farshad Far, M.; Safari, H.; Moradi, F.; Shirvani, H. Study of Genetic Relationships of Some Mint Species Using ISSR Markers. Crop Biotechnol. 2014, 3, 11-21.

115. Ibrahim, H.M.M. Assessment of Genetic Diversity and Relationships of Five Mentha Species Using RAPD Marker. Curr. Sci. Int. 2017, 6, 271-277.

116. Smolik, M.; Jadczak, D.; Rzepka-Plevneš, D.; Sękowska, A. Morphological and Genetic Variability of Chosen Mentha Species. Herba Pol. J. 2007, 53, 90-97.

117. De Matos Rodrigues, L.S. Phytochemical and Genetic Diversity in Mentha Species: Assessment, Valorization and Conservation. Ph.D. Thesis, Universidade Tecnica de Lisboa, Lisbon, Portugal, 2012.

118. Li, B.; Cantino, P.D.; Olmstead, R.G.; Bramley, G.L.C.; Xiang, C.-L.; Ma, Z.-H.; Tan, Y.-H.; Zhang, D.-X. A Large-Scale Chloroplast Phylogeny of the Lamiaceae Sheds New Light on Its Subfamilial Classification. Sci. Rep. 2016, 6, 34343. [CrossRef] 
119. Li, P.; Qi, Z.-C.; Liu, L.-X.; Ohi-Toma, T.; Lee, J.; Hsieh, T.-H.; Fu, C.-X.; Cameron, K.M.; Qiu, Y.-X. Molecular Phylogenetics and Biogeography of the Mint Tribe Elsholtzieae (Nepetoideae, Lamiaceae), with an Emphasis on Its Diversification in East Asia. Sci. Rep. 2017, 7, 2057. [CrossRef]

120. Wu, F.; Li, M.; Liao, B.; Shi, X.; Xu, Y. DNA Barcoding Analysis and Phylogenetic Relation of Mangroves in Guangdong Province, China. Forests 2019, 10, 56. [CrossRef]

121. De Mattia, F.; Bruni, I.; Galimberti, A.; Cattaneo, F.; Casiraghi, M.; Labra, M. A Comparative Study of Different DNA Barcoding Markers for the Identification of Some Members of Lamiacaea. Food Res. Int. 2011, 44, 693-702. [CrossRef]

122. Vilas, R.; Criscione, C.D.; Blouin, M.S. A Comparison between Mitochondrial DNA and the Ribosomal Internal Transcribed Regions in Prospecting for Cryptic Species of Platyhelminth Parasites. Parasitology 2005, 131, 839-846. [CrossRef] [PubMed]

123. Drew, B.T.; Sytsma, K.J. Phylogenetics, Biogeography, and Staminal Evolution in the Tribe Mentheae (Lamiaceae). Am. J. Bot. 2012, 99, 933-953. [CrossRef]

124. Draisma, S.G.A.; Eurlings, M.C.M.; Lim, P.-E. High Intra-Individual Sequence Variation in the Nuclear RDNA LSU-5S Intergenic Spacer in the Sargassaceae (Fucales, Phaeophyceae). J. Appl. Phycol. 2012, 24, 1373-1379. [CrossRef]

125. Babineau, M.; Gagnon, E.; Bruneau, A. Phylogenetic Utility of 19 Low Copy Nuclear Genes in Closely Related Genera and Species of Caesalpinioid Legumes. South Afr. J. Bot. 2013, 89, 94-105. [CrossRef]

126. Chen, J.; Zeng, Y.-F.; Liao, W.-J.; Yan, P.-C.; Zhang, J.-G. A Novel Set of Single-Copy Nuclear Gene Markers in White Oak and Implications for Species Delimitation. Tree Genet. Genomes 2017, 13, 50. [CrossRef]

127. Yasuda, N.; Taquet, C.; Nagai, S.; Fortes, M.; Fan, T.-Y.; Harii, S.; Yoshida, T.; Sito, Y.; Nadaoka, K. Genetic Diversity, Paraphyly and Incomplete Lineage Sorting of MtDNA, ITS2 and Microsatellite Flanking Region in Closely Related Heliopora Species (Octocorallia). Mol. Phylogenet. Evol. 2015, 93, 161-171. [CrossRef]

128. Waugh, J. DNA Barcoding in Animal Species: Progress, Potential and Pitfalls. BioEssays News Rev. Mol. Cell. Dev. Biol. 2007, 29, 188-197. [CrossRef]

129. Chase, M.W.; Salamin, N.; Wilkinson, M.; Dunwell, J.M.; Kesanakurthi, R.P.; Haidar, N.; Savolainen, V. Land Plants and DNA Barcodes: Short-Term and Long-Term Goals. Philos. Trans. R. Soc. Lond. B. Biol. Sci. 2005, 360, 1889-1895. [CrossRef]

130. Saini, A.; Reddy, S.K.; Jawali, N. Intra-Individual and Intra-Species Heterogeneity in Nuclear RDNA ITS Region of Vigna Species from Subgenus Ceratotropis. Genet. Res. 2008, 90, 299-316. [CrossRef] [PubMed]

131. Shiragaki, K.; Yokoi, S.; Tezuka, T. Phylogenetic Analysis and Molecular Diversity of Capsicum Based on RDNA-ITS Region. Horticulturae 2020, 6, 87. [CrossRef]

132. Bower, J.E.; Cooper, R.D.; Beebe, N.W. Internal Repetition and Intraindividual Variation in the RDNA ITS1 of the Anopheles Punctulatus Group (Diptera: Culicidae): Multiple Units and Rates of Turnover. J. Mol. Evol. 2009, 68, 66-79. [CrossRef] [PubMed]

133. McFadden, C.S.; Sánchez, J.A.; France, S.C. Molecular Phylogenetic Insights into the Evolution of Octocorallia: A Review. Integr. Comp. Biol. 2010, 50, 389-410. [CrossRef] [PubMed]

134. Xuan, Y.; Wu, Y.; Li, P.; Liu, R.; Luo, Y.; Yuan, J.; Xiang, Z.; He, N. Molecular Phylogeny of Mulberries Reconstructed from ITS and Two CpDNA Sequences. PeerJ 2019, 7. [CrossRef] [PubMed]

135. Xu, B.; Zeng, X.-M.; Gao, X.-F.; Jin, D.-P.; Zhang, L.-B. ITS Non-Concerted Evolution and Rampant Hybridization in the Legume Genus Lespedeza (Fabaceae). Sci. Rep. 2017, 7, 40057. [CrossRef]

136. Wan, D.; Sun, Y.; Zhang, X.; Bai, X.; Wang, J.; Wang, A.; Milne, R. Multiple ITS Copies Reveal Extensive Hybridization within Rheum (Polygonaceae), a Genus That Has Undergone Rapid Radiation. PLoS ONE 2014, 9, e89769. [CrossRef]

137. Montgomery, M.C. Incomplete Concerted Evolution in the Non-Hybrid Diploid Clematis Fremontii S. Watson (Ranunculaceae). Master's Thesis, University of Tennessee, Chattanooga, TN, USA, 2009.

138. King, M.G.; Roalson, E.H. Exploring Evolutionary Dynamics of NrDNA in Carex Subgenus Vignea (Cyperaceae). Syst. Bot. 2008, 33, 514-524. [CrossRef]

139. Meimberg, H.; Abele, T.; Bräuchler, C.; McKay, J.K.; Pérez de Paz, P.L.; Heubl, G. Molecular Evidence for Adaptive Radiation of Micromeria Benth. (Lamiaceae) on the Canary Islands as Inferred from Chloroplast and Nuclear DNA Sequences and ISSR Fingerprint Data. Mol. Phylogenet. Evol. 2006, 41, 566-578. [CrossRef]

140. Wang, X.; Chen, X.; Yang, P.; Wang, L.; Han, J. Barcoding the Dendrobium (Orchidaceae) Species and Analysis of the Intragenomic Variation Based on the Internal Transcribed Spacer 2. BioMed Res. Int. 2017, 2017, 2734960. [CrossRef]

141. Nieto Feliner, G.; Rosselló, J.A. Better the Devil You Know? Guidelines for Insightful Utilization of NrDNA ITS in Species-Level Evolutionary Studies in Plants. Mol. Phylogenet. Evol. 2007, 44, 911-919. [CrossRef]

142. Estensmo, E.L.F.; Maurice, S.; Morgado, L.; Martin-Sanchez, P.M.; Skrede, I.; Kauserud, H. The Influence of Intraspecific Sequence Variation during DNA Metabarcoding: A Case Study of Eleven Fungal Species. Mol. Ecol. Resour. 2020. [CrossRef]

143. Schoch, C.L.; Seifert, K.A.; Huhndorf, S.; Robert, V.; Spouge, J.L.; Levesque, C.A.; Chen, W.; Consortium, F.B. Nuclear Ribosomal Internal Transcribed Spacer (ITS) Region as a Universal DNA Barcode Marker for Fungi. Proc. Natl. Acad. Sci. USA 2012, 109, 6241-6246. [CrossRef]

144. Rojas, A.; Dvir, E.; Farkas, R.; Sarma, K.; Borthakur, S.; Jabbar, A.; Markovics, A.; Otranto, D.; Baneth, G. Phylogenetic Analysis of Spirocerca Lupi and Spirocerca Vulpis Reveal High Genetic Diversity and Intra-Individual Variation. Parasit. Vectors 2018, 11, 639. [CrossRef] 
145. Alquezar, D.E.; Hemmerter, S.; Cooper, R.D.; Beebe, N.W. Incomplete Concerted Evolution and Reproductive Isolation at the RDNA Locus Uncovers Nine Cryptic Species within Anopheles Longirostris from Papua New Guinea. BMC Evol. Biol. 2010, 10, 392. [CrossRef]

146. Fujisawa, T.; Barraclough, T.G. Delimiting Species Using Single-Locus Data and the Generalized Mixed Yule Coalescent Approach: A Revised Method and Evaluation on Simulated Data Sets. Syst. Biol. 2013, 62, 707-724. [CrossRef]

147. Flot, J.-F. CHAMPURU 1.0: A Computer Software for Unraveling Mixtures of Two DNA Sequences of Unequal Lengths. Mol. Ecol. Notes 2007, 7, 974-977. [CrossRef]

148. Popp, M. Disentangling the Reticulate History of Polyploids in Silene (Caryophyllaceae). Comprehensive Summaries of Uppsala Dissertations from the Faculty of Science and Technology n ${ }^{\circ}$ 924. Ph.D. Thesis, Uppsala University, Uppsala, Sweden, 2004.

149. Wu, C.I. The Genic View of the Process of Speciation. J. Evol. Biol. 2001, 14, 851-865. [CrossRef]

150. Soltis, P.S.; Soltis, D.E. Ancient WGD Events as Drivers of Key Innovations in Angiosperms. Curr. Opin. Plant Biol. 2016, 30, 159-165. [CrossRef]

151. Wang, W.; Wang, Y.; Lei, F.; Liu, Y.; Wang, H.; Chen, J. Incomplete Lineage Sorting and Introgression in the Diversification of Chinese Spot-Billed Ducks and Mallards. Curr. Zool. 2019, 65, 589-597. [CrossRef]

152. Šarić-Kundalić, B.; Fialová, S.; Dobeš, C.; Ölzant, S.; Tekel’ová, D.; Grančai, D.; Reznicek, G.; Saukel, J. Multivariate Numerical Taxonomy of Mentha Species, Hybrids, Varieties and Cultivars. Sci. Pharm. 2009, 77, 851-876. [CrossRef]

153. Mogosan, C.; Vostinaru, O.; Oprean, R.; Heghes, C.; Filip, L.; Balica, G.; Moldovan, R.I. A Comparative Analysis of the Chemical Composition, Anti-Inflammatory, and Antinociceptive Effects of the Essential Oils from Three Species of Mentha Cultivated in Romania. Molecules 2017, 22, 263. [CrossRef] [PubMed]

154. Harder, L.D.; Strelin, M.M.; Clocher, I.C.; Kulbaba, M.W.; Aizen, M.A. The Dynamic Mosaic Phenotypes of Flowering Plants. New Phytol. 2019, 224, 1021-1034. [CrossRef] [PubMed]

155. Sacco, T.; Peracino, V.; Maffei, M.E. Phenotypic Plasticity in Mentha Viridis Lavanduliodora. J. Essent. Oil Res. 1992, 4, $491-496$. [CrossRef]

156. Maffei, M.E.; Scannerini, S. UV-B Effect on Photomorphogenesis and Essential Oil Composition in Peppermint (Mentha Piperita L.). J. Essent. Oil Res. 2000, 12, 523-529. [CrossRef]

157. Mishra, A.; Jain, P.; Lal, R.K.; Dhawan, S.S. Trichomes and Yield Traits in Mentha Arvensis: Genotype Performance and Stability Evaluation. J. Herbs Spices Med. Plants 2018, 24, 1-14. [CrossRef]

158. Singh, V.R.; Lal, R.K. Genotype $\times$ Environment Interaction, Genetic Variability and Inheritance Pattern in Breeding Lines Including Varieties/Cultivars of Menthol Mint (Mentha Arvensis L.). J. Med. Aromat. Plant Sci. 2020, 42, 145-156.

159. Bertea, C.M.; Mucciarelli, M. Anatomy, physiology, biosynthesis, molecular biology, tissue culture and biotechnology of mint essential oil production Biosynthesis, Molecular Biology, Tissue Culture, and Biotechnology of Mint Essential Oil Production. In Mint. The Genus Mentha; Lawrence, B.M., Ed.; CRC Press: Boca Raton, FL, USA, 2007; pp. 41-85. ISBN 4213.6.20069.

160. Stayton, C.T. Are Our Phylomorphospace Plots so Terribly Tangled? An Investigation of Disorder in Data Simulated under Adaptive and Nonadaptive Models. Curr. Zool. 2020, 66, 565-574. [CrossRef]

161. Phillips, J.D.; Gillis, D.J.; Hanner, R.H. Incomplete Estimates of Genetic Diversity within Species: Implications for DNA Barcoding. Ecol. Evol. 2019, 9, 2996-3010. [CrossRef]

162. Formia, A.; Broderick, A.C.; Glen, F.; Godley, B.J.; Hays, G.C.; Bruford, M.W. Genetic Composition of the Ascension Island Green Turtle Rookery Based on Mitochondrial DNA: Implications for Sampling and Diversity. Endanger. Species Res. 2007, 3, 145-158. [CrossRef]

163. Egeland, T.; Salas, A. Estimating Haplotype Frequency and Coverage of Databases. PLoS ONE 2008, 3, e3988. [CrossRef]

164. Luo, A.; Lan, H.; Ling, C.; Zhang, A.; Shi, L.; Ho, S.Y.W.; Zhu, C. A Simulation Study of Sample Size for DNA Barcoding. Ecol. Evol. 2015, 5, 5869-5879. [CrossRef]

165. Jullien, F. Mint. In Biotechnology in Agriculture and Forestry 59-Transgenic Crops IV; Nagata, T., Lörz, H., Widholm, J.M., Eds.; Springer: Berlin/Heidelberg, Germany, 2007; pp. 435-466.

166. Vining, K.J.; Hummer, K.E.; Bassil, N.V.; Lange, B.M.; Khoury, C.K.; Carver, D. Crop Wild Relatives as Germplasm Resource for Cultivar Improvement in Mint (Mentha L.). Front. Plant Sci. 2020, 11. [CrossRef]

167. Elliott, N.E. Testing Hypotheses of Hybridization in Mentha Spicata and M. Canadensis Using Molecular Data. Available online: https://digitalcommons.murraystate.edu/postersatthecapitol/2005/WKU/5/ (accessed on 19 April 2021).

168. Bräuchler, C.; Meimberg, H.; Heubl, G. Molecular Phylogeny of the Genera Digitalis L. and Isoplexis (Lindley) Loudon (Veronicaceae) Based on ITS- and TrnL-F Sequences. Plant Syst. Evol. 2004, 248, 111-128. [CrossRef]

169. Stephens, M.; Smith, N.J.; Donnelly, P. A New Statistical Method for Haplotype Reconstruction from Population Data. Am. J. Hum. Genet. 2001, 68, 978-989. [CrossRef]

170. Stephens, M.; Scheet, P. Accounting for Decay of Linkage Disequilibrium in Haplotype Inference and Missing-Data Imputation. Am. J. Hum. Genet. 2005, 76, 449-462. [CrossRef]

171. Flot, J.-F.; Tillier, A.; Samadi, S.; Tillier, S. Phase Determination from Direct Sequencing of Length-Variable DNA Regions. Mol. Ecol. Notes 2006, 6, 627-630. [CrossRef]

172. Khan, N.; Dhawan, S.S. Role of Molecular Markers in Assessing Genetic Diversity in Mentha: A Review. Sci. J. Genet. Gene Ther. 2016, 2, 022-026. [CrossRef] 
173. Salama, A.M.; Osman, E.A.; El-Tantawy, A.A. Taxonomical Studies on Four Mentha Species Grown in Egypt through MorphoAnatomical Characters and SCOT Genetic Markers. Plant Arch. 2019, 19, 2273-2286.

174. Bylesjö, M.; Segura, V.; Soolanayakanahally, R.Y.; Rae, A.M.; Trygg, J.; Gustafsson, P.; Jansson, S.; Street, N.R. LAMINA: A Tool for Rapid Quantification of Leaf Size and Shape Parameters. BMC Plant Biol. 2008, 8. [CrossRef]

175. Katoh, K.; Kuma, K.I.; Toh, H.; Miyata, T. MAFFT Version 5: Improvement in Accuracy of Multiple Sequence Alignment. Nucleic Acids Res. 2005, 33, 511-518. [CrossRef] [PubMed]

176. Suchard, M.A.; Lemey, P.; Baele, G.; Ayres, D.L.; Drummond, A.J.; Rambaut, A. Bayesian Phylogenetic and Phylodynamic Data Integration Using BEAST 1.10. Virus Evol. 2018, 4. [CrossRef] [PubMed]

177. Darriba, D.; Taboada, G.L.; Doallo, R.; Posada, D. JModelTest 2: More Models, New Heuristics and Parallel Computing. Nat. Methods 2012, 9, 772. [CrossRef] [PubMed]

178. Rambaut, A.; Drummond, A.J.; Xie, D.; Baele, G.; Suchard, M.A. Posterior Summarization in Bayesian Phylogenetics Using Tracer 1.7. Syst. Biol. 2018, 67, 901-904. [CrossRef] [PubMed]

179. Spöri, Y.; Flot, J. HaplowebMaker and CoMa: Two Web Tools to Delimit Species Using Haplowebs and Conspecificity Matrices. Methods Ecol. Evol. 2020, 11, 1434-1438. [CrossRef]

180. Bandelt, H.J.; Forster, P.; Röhl, A. Median-Joining Networks for Inferring Intraspecific Phylogenies. Mol. Biol. Evol. 1999, 16, 37-48. [CrossRef]

181. Flot, J.-F.; Couloux, A.; Tillier, S. Haplowebs as a Graphical Tool for Delimiting Species: A Revival of Doyle's “Field for Recombination" Approach and Its Application to the Coral Genus Pocillopora in Clipperton. BMC Evol. Biol. 2010, 10, 372. [CrossRef]

182. Debortoli, N.; Li, X.; Eyres, I.; Fontaneto, D.; Hespeels, B.; Tang, C.Q.; Flot, J.-F.; Van Doninck, K. Genetic Exchange among Bdelloid Rotifers Is More Likely Due to Horizontal Gene Transfer Than to Meiotic Sex. Curr. Biol. 2016, 26, 723-732. [CrossRef]

183. Sharma, S. Applied Multivariate Techniques; John Wiley \& Sons, Inc.: Hoboken, NJ, USA, 1996.

184. Ripley, B.; Venables, B.; Bates, D.M.; Hornik, K.; Gebhardt, A.; Firth, D. Package 'MASS'. Support Functions and Datasets for Venables and Ripley's MASS. Available online: https://cran.r-project.org/web/packages/MASS/MASS.pdf/ (accessed on 19 April 2021).

185. Witten, D. Package 'penalizedLDA'. Package Penalized Classification Using Fishers's Linear Discriminant. Available online: https:/ / cran.r-project.org/web/packages/penalizedLDA/penalizedLDA.pdf (accessed on 19 April 2021).

186. Friedman, J.; Hastie, T.; Tibshirani, R.; Narasimhan, B.; Tay, K.; Simon, N.; Qian, J. Package 'glmnet'. Lasso and Elastic-Net Regularized Generalized Linear Models. Available online: https://cran.r-project.org/web/packages/glmnet/glmnet.pdf (accessed on 19 April 2021).

187. Cadima, J.; Orestes Cerdeira, J.; Duarte Silva, P.; Minhoto, M. Package 'subselect'. Selecting Variable Subsets. Available online: https://cran.r-project.org/web/packages/subselect/subselect.pdf (accessed on 19 April 2021).

188. Jolliffe, I.T. Principal Component Analysis, 2nd ed.; Springer Series in Statistics; Springer: New York, NY, USA, 2002.

189. Heylen, O. Principal Component Analysis of Nested Binary Data. In Characteristics and Application to Ecology; University Center for Statistics, KU Leuven: Leuven, Belgium, 2007.

190. Witten, D.M.; Tibshirani, R. Penalized Classification Using Fisher's Linear Discriminant. J. R. Stat. Soc. Ser. B Stat. Methodol. 2011, 73, 753-772. [CrossRef]

191. Wickham, H.; Chang, W.; Henry, L.; Takahashi, K.; Wilke, C.; Woo, K.; Yutani, H.; Dunnington, D. Ggplot2: Create Elegant Data Visualisations Using the Grammar of Graphics—Ggplot2-Package; RStudio: Boston, MA, USA, 2020.

192. Reynolds, A. Cubemaker; Altius Institute: Seattle, WA, USA, 2015. 